\title{
Research Soure \\ Optimization of an Ammonia Assay based on Transmembrane pH-gradient Polymersomes
}

\author{
Anastasia Spyrogianni \\ ETH Zurich \\ Charlotte Gourmel \\ ETH Zurich \\ Leopold Hofmann \\ ETH Zurich \\ Jessica Marbach \\ ETH Zurich \\ Jean-Christophe Leroux ( $\sim$ jleroux@ethz.ch ) \\ ETH Zurich
}

\section{Research Article}

Keywords: ammonia, Transmembrane , Polymersomes, microplate-based assay

Posted Date: May 26th, 2021

DOl: https://doi.org/10.21203/rs.3.rs-538173/v1

License: (c) (1) This work is licensed under a Creative Commons Attribution 4.0 International License.

Read Full License

Version of Record: A version of this preprint was published at Scientific Reports on November 11th, 2021. See the published version at https://doi.org/10.1038/s41598-021-01137-1. 


\title{
Optimization of an ammonia assay based on transmembrane $\mathbf{p H}$-gradient polymersomes
}

\author{
Anastasia Spyrogianni ${ }^{\ddagger}$, Charlotte Gourmel $^{\ddagger}$, Leopold Hofmann, Jessica \\ Marbach, Jean-Christophe Leroux* \\ Institute of Pharmaceutical Sciences, Department of Chemistry and Applied Biosciences, \\ ETH Zurich, Vladimir-Prelog-Weg 3, CH-8093 Zurich, Switzerland \\ ${ }^{\ddagger}$ C. Gourmel and A. Spyrogianni contributed equally to this work \\ *Author to whom correspondence should be addressed: jleroux@ethz.ch
}

Submitted to:

Scientific Reports

18 May 2021 


\section{Abstract}

Reliable ammonia quantification assays are essential for monitoring ammonemia in patients with liver diseases. In this study, we describe the development process of a microplate-based assay for accurate, precise, and robust ammonia quantification in biological fluids, following regulatory guidelines on bioanalytical method validation. The assay is based on transmembrane $\mathrm{pH}$-gradient polymersomes that encapsulate a $\mathrm{pH}$-sensitive ratiometric fluorophore, the fluorescence signal of which correlates with the ammonia concentration in the sample. Using four-parameter logistic regression, the assay had a large quantification range (30-800 $\mu \mathrm{M}$ ammonia). As for selectivity, the presence of amino acids or pyruvate (up to clinically relevant concentrations) showed no assay interference. In samples with low bilirubin levels, polymersomes containing the fluorophore pyranine provided accurate ammonia quantification. In samples with high bilirubin concentrations, billirubin's optical interference was alleviated when replacing pyranine with a close to near-infrared hemicyanine fluorophore. Finally, the assay could correctly retrieve the ammonia concentration in ammonia-spiked human plasma samples, which was confirmed by comparing our measurements with the data obtained using a commercially available point-of-care device for ammonia. 


\section{Introduction}

Blood ammonia is increasingly considered a central prognostic analyte in a number of lifethreatening conditions ${ }^{1-3}$. Ammonia is a potentially neurotoxic compound that is mainly produced by the catabolism of amino acids and the hydrolysis of urea in the gastrointestinal tract ${ }^{4}$. In healthy subjects, blood ammonia is kept at homeostasis through its involvement in the synthesis of nitrogen-containing compounds and its elimination by the urea cycle in the liver ${ }^{4}$. Defects in these pathways, due to inborn errors of metabolism (e.g. urea cycle disorders) or acquired diseases (e.g. liver diseases, drug toxicity), lead to an elevated ammonia level in systemic circulation ${ }^{3-5}$. A condition with plasma ammonia levels $>50 \mu \mathrm{M}$ in adults and $>100 \mu \mathrm{M}$ in newborns is defined as hyperammonemia ${ }^{5,6}$. Concentrations greater than $500 \mu \mathrm{M}$ have been reported for children with inborn errors of metabolism².

Patients with hyperammonemia may develop hepatic encephalopathy, which manifests as a wide spectrum of neurological or psychiatric abnormalities ranging from mild cognitive and behavioral alterations to coma ${ }^{8}$. Even the mildest forms of hepatic encephalopathy negatively impact the quality of life of both patients and caregivers, while overt and recurrent episodes of hepatic encephalopathy are related to poor prognosis, mortality, and increased healthcare burden ${ }^{9}$.

Measuring blood ammonia levels is of key importance for diagnosing inborn errors of metabolisms or drug toxicity in patients presenting neurological abnormalities without apparent liver problems, and may have a prognostic value in patients with acute liver failure $^{1,3,10}$. Despite the wide interest in developing ammonia sensors ${ }^{11-14}$, the manufacturing complexity or the lack of a full bioanalytical method validation hamper many - otherwise promising - technologies to meet clinical requirements and make it to the market. In clinical settings, ammonia is commonly measured in blood plasma samples using an enzymatic assay, performed in clinical chemistry analyzers ${ }^{15,16}$. Although many of the currently available enzymatic assays have a wide quantification range (e.g. $8.8-1,174.2 \mu \mathrm{M}$ for the $\mathrm{L}^{\mathrm{K}} \mathrm{K}^{\circledR}$ assay from Sekisui Diagnostics), assay procedure is often quite complex resulting in long turnaround 
times ${ }^{16}$. Furthermore, high plasma ammonia values may be obtained as an artefact due to incorrect blood sampling and processing ${ }^{7}$. An alternative in vitro diagnostic method, which has been implemented both in clinical chemistry analyzers (for plasma) and as a point-of-care (POC) device (for blood), is based on sample alkalization, ammonia gas microdiffusion, and colorimetry ${ }^{15,16}$. While data turnaround times for POC devices are faster ${ }^{16}$, the quantification range is relatively narrow $(7-286 \mu \mathrm{M})$.

Here, we describe the optimization process of a microplate-based assay for accurate, precise, and robust ammonia quantification in biological fluids, using transmembrane $\mathrm{pH}$ gradient polymeric vesicles (polymersomes, PoSo) that encapsulate a $\mathrm{pH}$-sensitive ratiometric fluorophore. PoSo were selected as they have relatively stable membranes ${ }^{17}$ and are less permeable and leaky ${ }^{18-20}$, and therefore less prone to interferences and/or loss of pH gradient than liposomes ${ }^{21,22}$. Once the ammonia-containing sample (e.g. plasma) is mixed with the PoSo suspension, uncharged ammonia molecules diffuse into the vesicle's acidic core, where they ionize to ammonium and then become trapped in the PoSo ${ }^{14}$. The $\mathrm{pH}$ inside the PoSo hence increases and the fluorescence signal of the encapsulated $\mathrm{pH}$-sensitive dye changes in relation to the ammonia concentration in the sample ${ }^{14}$. In this study, we optimized the assay with a high standard of practice and followed regulatory guidelines on bioanalytical method validation ${ }^{23-25}$. Furthermore, the assay was challenged against various concentrations of potential interferents, such as amino acids ${ }^{26}$, pyruvate ${ }^{27}$, and bilirubin ${ }^{28}$, while its performance in human plasma was compared to a commercial POC device.

\section{Materials and Methods}

\section{Diblock copolymer synthesis}

A polystyrene-poly(ethylene glycol) diblock copolymer (PS- $b-P E G$ ) consisting of a PEG block with a number-averaged molecular weight $\left(M_{n}\right)$ of 2,000 Da and a polystyrene (PS) block with a $M_{n}$ of 3,500-4,500 Da was synthesized by atom transfer radical polymerization ${ }^{29,30}$. Details on the synthesis are provided in the Supplementary Methods. 


\section{Diblock copolymer characterization}

The PS- $b$-PEG composition was analyzed by ${ }^{1} \mathrm{H}$ NMR spectroscopy. All NMR spectra were recorded on a Bruker AV-400 spectrometer at $400 \mathrm{MHz}$ (Bruker, MA, USA). Resonances are reported as chemical shifts $(\delta)$ in parts per million (ppm), and the residual undeuterated solvent peak or tetramethylsilane were used for spectral calibration. To determine the PS- $b$ PEG composition, the large peak of PEG (45 $\times \mathrm{CH}_{2}-\mathrm{CH}_{2}, \mathrm{~m}, \delta 3.4-3.5 \mathrm{ppm}$ ) was compared with the aromatic styrene protons peak $\left(n \times \mathrm{C}_{6} \mathrm{H}_{5}, \mathrm{~m}, 6.2-7.2 \mathrm{ppm}\right)$. The copolymer dispersity (Đ) was assessed by gel permeation chromatography, as detailed in the Supplementary

\section{Methods.}

\section{PoSo preparation}

A solvent emulsification method ${ }^{31}$ was used to prepare the PoSo. A solution of the polymer in an organic solvent $\left(300 \mathrm{mg} / \mathrm{mL}\right.$ PS $4 \mathrm{k}-b-\mathrm{PEG}_{2 \mathrm{k}}$ in dichloromethane (DCM; Acros Organics, Thermo Fisher Scientific, MA, USA) was injected slowly into a vigorously agitated aqueous solution to form an emulsion. For transmembrane $\mathrm{pH}$-gradient PoSo (made for ammonia sensing), the aqueous phase (constitutive of the PoSo inner core) consisted of citric acid (CA) buffer (5.5 mM; osmolality adjusted to $300 \mathrm{mOsm} / \mathrm{kg}$ using $\mathrm{NaCl}$; $\mathrm{pH}$ appropriately adjusted with $\mathrm{HCl}$ and/or $\mathrm{NaOH}$ ) and a $\mathrm{pH}$-sensitive fluorescent dye. For PoSo made with the same inner and outer $\mathrm{pH}\left(\mathrm{pH}_{\text {in }}=\mathrm{pH}_{\text {out }}\right.$; made for optical properties studies $)$, the aqueous dye solution was prepared in CA buffer $(5.5 \mathrm{mM})$ for $\mathrm{pH}_{\text {in }} \leq 6.5$, phosphate buffer $(50 \mathrm{mM})$ for 6.5 $<\mathrm{pH}_{\text {in }} \leq 8.0$, and borate buffer $(50 \mathrm{mM})$ for $\mathrm{pH}_{\text {in }}>8.5$. For buffer preparation, the following salts were used: CA monohydride for analysis Emsure ${ }^{\circledR}$, ACS, ISO, Reag. Ph Eur (Merck, Switzerland) for CA buffers, potassium dihydrogen phosphate for analysis Emsure $\Re$, ISO (Merck) for phosphate buffers and borax (Hänseler AG, Switzerland) for borate buffers.

The dye aqueous phase ( 1 or $3 \mathrm{~mL}$ ) was added to a $5 \mathrm{~mL}$ Eppendorf tube and agitation was initiated at $30 \mathrm{krpm}$ using a mechanical homogenizer (Polytron PT 1300 D, Kinematica AG, Switzerland), equipped with a PT-DA 05/2EC-E085 or PT-DA $1607 / 2$ EC probe for 1 or $3 \mathrm{~mL}$ batches, respectively. An appropriate volume of the polymer solution was then injected at 
$6 \mathrm{~mL} / \mathrm{h}$ with a syringe pump (Fusion 101, Chemyx Inc, TX, USA) through a Hamilton needle (0.8 $\mathrm{mm}$ diameter, $80 \mathrm{~mm}$ length) that was bended at a $90^{\circ}$ angle and inserted with its tip approximately in the middle of the solution. The injected polymer solution volume was $20 \mu \mathrm{L}$ for the $1 \mathrm{~mL}$ PoSo-HPTS batches prepared initially (i.e. before adjusting the conditions for minimization of bilirubin interference) as well as for PoSo-Lyso and PoSo-SNARF batches. For PoSo-HPTS prepared thereafter as well as for PoSo-hCy batches, the injected polymer solution volume was $30 \mu \mathrm{L}$ for $1 \mathrm{~mL}$ batches or $90 \mu \mathrm{L}$ for $3 \mathrm{~mL}$ batches. After complete injection of the polymer solution, emulsification was continued for 4 or 6 min depending on batch size ( 1 or $3 \mathrm{~mL}$, respectively). Emulsification was followed by rotary evaporation ( $40{ }^{\circ} \mathrm{C}, 700 \mathrm{hPa}$ ) of residual DCM for 5 or $12 \mathrm{~min}$, respectively. Multiple 1 or $3 \mathrm{~mL}$ batches were typically prepared and pooled to obtain the desired final volume of suspension for further purification.

Four different $\mathrm{pH}$-sensitive fluorescent dyes were tested for encapsulation in PoSo: pyranine (8-hydroxypyrene-1,3,6-trisulfonic acid trisodium salt, HPTS), hCy (6-hydroxy-4-[(E)-2(1,3,3-trimethyl-3H-1 $\lambda^{5}$-indol-2-yl)ethenyl]-2,3-dihydro- $1 \mathrm{H}$-xanthene-5,7-disulfonic acid) ${ }^{32}$, Lyso- $\mathrm{pH}^{33}$, or seminaphtharhodafluor (SNARF $\left.{ }^{\mathrm{TM}}-4 \mathrm{~F}\right)$.

\section{HPTS encapsulating PoSo (PoSo-HPTS)}

HPTS (Acros Organics, Thermo Fisher Scientific) at concentrations ([HPTS] in) of 1 or $2.5 \mathrm{mM}$ was used as the inner core solution. PoSo-HPTS were made for optical properties studies with $\mathrm{pH}_{\text {in }}=\mathrm{pH}_{\text {out }}$ or for ammonia sensing with $\mathrm{pH}_{\text {out }}>\mathrm{pH}_{\text {in }}$.

\section{hCy encapsulating PoSo (PoSo-hCy)}

hCy at concentrations ([hCy ]in) of 500 or $250 \mu \mathrm{M}$ was used as the inner core solution. The dye hCy was synthesized by Synhet Inc. (Lithuania), following a previously published method. ${ }^{32}$ PoSo-hCy were made for optical properties studies with $\mathrm{pH}_{\text {in }}=\mathrm{pH}_{\text {out }}$ or for ammonia sensing with $\mathrm{pH}_{\text {out }}>\mathrm{pH}$.

\section{Lyso-pH encapsulating PoSo (PoSo-Lyso)}

Lyso-pH at concentrations ([Lyso-pH] in) of 50 or $200 \mu \mathrm{M}$ was used as the inner core solution. 
The dye Lyso- $\mathrm{pH}^{33}$ was purchased from 007 Chemicals (The Netherlands). In PoSo-Lyso batches made with the surfactant sodium dodecyl sulfate (SDS, ACS reagent, $\geq 99.0 \%$, SigmaAldrich, Merck, Switzerland), 0.09 mM SDS was added to the inner core solution. PoSo-Lyso were made for optical properties studies with $\mathrm{pH}_{\text {in }}=\mathrm{pH}_{\text {out }}$.

\section{SNARF ${ }^{\mathrm{TM}}$-4F encapsulating PoSo (PoSo-SNARF)}

SNARF $^{\mathrm{TM}}$-4F (Thermo Fisher Scientific) at a concentration of $100 \mu \mathrm{M}$ was used as the inner core solution. PoSo-SNARF were made for optical properties studies with $\mathrm{pH}_{\text {in }}=\mathrm{pH}_{\text {out }}$.

\section{PoSo purification}

\section{General procedure}

PoSo purification consisted of removal of the non-encapsulated dye and buffer exchange of the outer medium. For PoSo made for ammonia sensing, the outer medium was phosphate buffer $(50 \mathrm{mM})$ for $6.5<\mathrm{pH}_{\text {out }} \leq 8.0$ or borate buffer $(50 \mathrm{mM})$ for $\mathrm{pH}_{\text {out }}>8.5$. For PoSo made for optical properties studies, the outer medium was CA buffer $(5.5 \mathrm{mM})$ for $\mathrm{pH}_{\text {out }} \leq 6.5$, phosphate buffer $(50 \mathrm{mM})$ for $6.5<\mathrm{pH}_{\text {out }} \leq 8.0$, or borate buffer $(50 \mathrm{mM})$ for $\mathrm{pH}_{\text {out }}>8.5$. The osmolality of all buffer solutions was adjusted to $300 \mathrm{mOsm} / \mathrm{kg}$ using $\mathrm{NaCl}$.

PoSo were purified by group separation using PD-10 desalting columns (Cytiva, UK), adapting the manufacturer's gravity protocol. The columns were first washed with $25 \mathrm{~mL}$ outer medium. When larger batches were needed, the eluates of multiple columns were pooled to obtain the final PoSo batch to be characterized and used for ammonia sensing.

\section{POSO-HPTS}

During purification, $1 \mathrm{~mL}$ PoSo-HPTS suspension and $1.5 \mathrm{~mL}$ outer medium were added to the desalting column and the flow through was discarded, after which $1.7 \mathrm{~mL}$ outer medium was added and the eluate containing the PoSo-HPTS was collected.

\section{PoSo-hCy}

For PoSo-hCy, a pre-purification step with Lewatit $^{\circledR}$ VP OC 1064 MD PH adsorbent beads (Lanxess, Germany) was included ( $200 \mathrm{mg}$ beads $/ \mathrm{mL}$ suspension) by vortexing the 
unpurified PoSo-hCy with the resin for $10 \mathrm{~min}$. Thanks to the pre-purification, PD-10 column sample loading could be increased while keeping a good performance: i.e. $2.5 \mathrm{~mL}$ PoSo-hCy suspension and $0.5 \mathrm{~mL}$ outer medium were loaded, the flow through was discarded and the elution was performed with $3 \mathrm{~mL}$ outer medium.

\section{PoSo-Lyso}

During purification, $0.5 \mathrm{~mL}$ PoSo-Lyso suspension and $2 \mathrm{~mL}$ outer medium were added to the desalting column and the flow through was discarded, after which $1.4 \mathrm{~mL}$ outer medium was added and the eluate containing the PoSo-Lyso was collected.

\section{POSO-SNARF}

The purification procedure was identical to PoSo-HPTS.

\section{Polymer quantification in PoSo suspensions}

The quantification of the polymer in PoSo samples relied on the absorbance of polystyrene at $270 \mathrm{~nm}$. For PoSo-HPTS, a stock solution $(2 \mathrm{mg} / \mathrm{mL}$ ) of the polymer batch used for PoSo-HPTS synthesis was prepared in a mixture of outer medium buffer ( 2 or 5 vol\%) in $N, N$ dimethylformamide (DMF, Acros Organics, Thermo Fisher Scientific). The stock solution was then appropriately diluted with the buffer/DMF mixture to prepare a series of polymer calibrants (5 non-zero levels, $0.03-1 \mathrm{mg} / \mathrm{mL}$ ), while aliquots of the PoSo-HPTS suspension were mixed with DMF to obtain a final suspension concentration of 2 or 5 vol\%. Calibrants and samples were vortexed vigorously and centrifuged $\left(18,000 \times g, 4^{\circ} \mathrm{C}, 10 \mathrm{~min}\right)$. The absorbance of the supernatants was measured at $270 \mathrm{~nm}$ in UV-star ${ }^{\circledR}$ 96-well transparent microplates (Greiner Bio-One, Switzerland) $\left(100 \mu \mathrm{L} /\right.$ well) using the Infinite ${ }^{\circledR}$ M200 or M200 Pro plate reader (Tecan, Switzerland). For PoSo-hCy, a similar procedure was followed but instead of DMF alone a DMF/dimethyl sulfoxide (DMSO) solvent mixture at a $1: 1$ volume ratio was used to prepare the calibrants and PoSo samples. Furthermore, the calibration curve was extended to $2 \mathrm{mg} / \mathrm{mL}$ ( 8 non-zero calibrants) and the centrifugation time was reduced to 8 min, which was sufficient for sedimentation of the insoluble buffer salts in this buffer/solvent mixture. 


\section{Dye quantification in PoSo suspensions}

\section{POSO-HPTS}

For PoSo-HPTS, calibration standard solutions (8 non-zero levels, $1-50 \mu \mathrm{M}$ ) of HPTS in outer buffer were prepared from a $100 \mu \mathrm{M}$ HPTS stock solution in the same buffer. Aliquots of each calibrant and the PoSo suspension were then diluted to 2 vol\% in DMF, vortexed vigorously, and centrifuged $\left(18,000 \times g, 4^{\circ} \mathrm{C}, 10 \mathrm{~min}\right)$. The fluorescence of the supernatants $(100 \mu \mathrm{L} /$ well $)$ was measured ( $\lambda_{\mathrm{exc}}=370 \mathrm{~nm}, \lambda_{\mathrm{em}}=416 \mathrm{~nm}$ ) in polypropylene 96 -well black microplates (Greiner Bio-One) using the Infinite ${ }^{\circledR}$ M200 or M200 Pro plate reader (Tecan).

\section{PoSo-hCy}

For PoSo-hCy, a similar procedure to that of PoSo-HPTS was followed but with the following modifications: hCy calibrants ( 8 non-zero levels, $20-180 \mu \mathrm{M}$ ) were prepared from a $2 \mathrm{mM}$ hCy stock solution in outer medium buffer, a DMF:DMSO mixture ( $1: 1$ by volume) was used instead of DMF alone, the centrifugation time was reduced to $8 \mathrm{~min}$, and fluorescence was measured at $\lambda_{\mathrm{exc}}=625 \mathrm{~nm}, \lambda_{\mathrm{em}}=735 \mathrm{~nm}$.

\section{PoSo-Lyso}

For PoSo-Lyso, calibration standard solutions (8 non-zero levels, 3-100 $\mu \mathrm{M}$ ) of Lyso-pH in outer medium buffer were prepared from a $100 \mu \mathrm{M}$ Lyso-pH stock solution in the same buffer. Aliquots of each calibrant and the PoSo suspension were then diluted to $5 \mathrm{vol} \%$ in DMF, vortexed vigorously, and centrifuged $\left(18,000 \times \mathrm{g}, 4{ }^{\circ} \mathrm{C}, 10 \mathrm{~min}\right)$. The fluorescence of the supernatants was measured $\left(\lambda_{\mathrm{exc}}=655 \mathrm{~nm}, \lambda_{\mathrm{em}}=755 \mathrm{~nm}\right)$.

\section{POSO-SNARF}

In the case of PoSo-SNARF, the nominal dye concentration was used as these PoSo could not be used for ammonia sensing. Notably, quantification in DMF is not possible as SNARF ${ }^{\mathrm{TM}}-4 \mathrm{~F}$ loses absorbance in this solvent.

\section{PoSo size measurements}

The PoSo size was measured by laser diffraction (Mastersizer 2000, Malvern Instruments, UK) 
in ultrapure water with the following settings: refractive indices for sample and water: 1.55 and 1.33, respectively; background and sample measurement time: $30 \mathrm{~s}$ each; number of measurements: 3; delay between measurements: 2 s; stirrer speed: 3,500 rpm. The sample volume was adjusted so that an obscuration $>0.5 \%$ was achieved. PS microparticles of $7 \mu \mathrm{m}$ average diameter (Sigma 78462, Merck) were used as a reference sample.

\section{Fluorescence of free HPTS vs. PoSo-HPTS}

HPTS fluorescence excitation spectra were measured in a 96-well black microplate (polypropylene, f-bottom, Greiner Bio-One) using the Infinite ${ }^{\circledR}$ M200 Pro plate reader (Tecan). Wells were loaded with $250 \mu \mathrm{L},[\mathrm{HPTS}]_{\text {well }}=2 \mu \mathrm{M}$ for the dye in solution and with $200 \mu \mathrm{L}$, [HPTS $]_{\text {well }} \approx 5 \mu \mathrm{M}$ for the PoSo-HPTS.

\section{PoSo-based ammonia assay}

Calibration standards and QC solutions of ammonia were prepared by dilution in phosphate buffered saline (PBS, Invitrogen, Thermo Fisher Scientific, MA, USA) of a $0.1 \mathrm{M} \mathrm{NH}_{4} \mathrm{Cl}_{(\mathrm{aq})}$ analytical standard solution for ion-selective electrodes (Sigma 09683, Merck). Calibrants and QCs were prepared independently: two separate stock solutions of $1000 \mu \mathrm{M} \mathrm{NH} 4^{+}{ }_{(a q)}$ in PBS were prepared and further diluted, one of them used for the calibrants and the other one for QCs. For each calibrant level, one solution per calibrant was prepared but measured in replicate wells. Pure PBS served as blank. For each QC level, replicate solutions were independently prepared.

For the assay, an aliquot of $z \mu \mathrm{L}$ of calibrant, QC, blank, or human plasma sample was mixed in a 96-well black microplate (PS, f-bottom, Greiner Bio-One) with $100-z \mu \mathrm{L}$ (for PoSoHPTS) or $200-z \mu \mathrm{L}$ (for PoSo-hCy) of a PoSo master mix using an electronic multichannel pipette (VOYAGER, Integra Biosciences, UK). For a sample volume fraction $\varphi=40 \mathrm{vol} \%, 40 \mu \mathrm{L}$ of sample and $60 \mu \mathrm{L}$ of PoSo-HPTS master mix were added per well. Once plate loading was complete, incubation took place in the dark at $20-25^{\circ} \mathrm{C}$ for $10 \mathrm{~min}$ and plate covered with its lid (for PoSo-HPTS) or for 5 min and plate not covered (for PoSo-hCy), unless stated otherwise. Well-wise fluorescence measurements were then performed with the Infinite ${ }^{\circledR}$ M200 Pro plate 
reader $\left(\right.$ Tecan) at $\lambda_{\text {exc }}=416 \mathrm{~nm}$ and $455 \mathrm{~nm}, \lambda_{\mathrm{em}}=515 \mathrm{~nm}$ for PoSo-HPTS or at $\lambda_{\mathrm{exc}}=$ $630 \mathrm{~nm}, \lambda_{\mathrm{em}}=682 \mathrm{~nm}$ and $712 \mathrm{~nm}$ for PoSo-hCy. The master mix was prepared by diluting the PoSo product batch with the outer medium buffer so that the desired final dye or polymer concentration in the wells could be reached ([HPTS $]_{\text {assay }}=0.4$ or $2.5 \mu \mathrm{M}$ for PoSo-HPTS, and $[\text { Polymer }]_{\text {assay }}=1.3 \mathrm{mg} / \mathrm{mL}$ for PoSo-hCy).

\section{Human plasma}

Human plasma was purchased from BioIVT (UK) with the following characteristics: healthy donors, pooled gender, tested negative against several pathogens including hepatitis virus, $\mathrm{K}_{2}$ EDTA anticoagulant collection, aliquoted after collection, frozen at $-80{ }^{\circ} \mathrm{C}$, shipped on dry ice, and stored immediately at $-80^{\circ} \mathrm{C}$ once received to prevent any freeze-thaw cycles. On the day of the experiment, an aliquot was thawed on ice and experiments were performed within $2.5 \mathrm{~h}$ after thawing. Throughout this time, the sample was kept on ice as recommended for ammonia quantification in plasma. The total bilirubin content of the plasma samples was measured with a commercial kit (bilirubin assay kit, LOT\# 3305897, Sigma-Aldrich, Merck).

\section{PocketChem $^{\mathrm{TM}}$ Blood Ammonia Analyzer}

The PocketChem ${ }^{\mathrm{TM}}$ Blood Ammonia Analyzer (Arkray, Japan) was used following the manufacturer's recommendation in the package insert and Q\&A document. Namely, the F-6 mode was used for measurements in plasma instead of the F-mode written on the stripes, which is recommended for measurements in blood. In brief, $20 \mu \mathrm{L}$ of sample were added onto the strip using a micropipette and after $180 \mathrm{~s}$ the filter of the strip was removed swiftly. For the measurement to be performed, the strip was inserted into the device and the device lid was closed.

The unspiked plasma aliquot was measured once right after the plasma was thawed and twice at the end of the PoSo ammonia assay experiments (i.e. $\sim 1-2 \mathrm{~h}$ after thawing) to ensure ammonia levels had not risen within the course of the experiment. Ammonia-spiked plasma samples were measured in duplicate. 


\section{Interference testing}

The amino acids selected to be tested as potential interferents for the PoSo-HPTS ammonia assay were: L-lysine monohydrochloride (Lys; 99.5\%), L-methionine (Met; 99.5\%) and Lphenylalanine (Phe; 99.0\%), all obtained from Merck. Sodium pyruvate (Pyr; for analysis, AppliChem, Germany) and bilirubin conjugate, ditaurate, disodium salt (Bil; Calbiochem, Merck) were also tested.

In the initial interference evaluation, $[\mathrm{HPTS}]_{\text {in }}=1 \mathrm{mM},[\mathrm{HPTS}]_{\text {well }}=0.4 \mu \mathrm{M}, \mathrm{pH}_{\text {in }} 6.0, \mathrm{pH}_{\text {out }}$ 8.2 , and $\varphi=40$ vol\% were used. In a typical experiment, a stock solution of the interferent was prepared at $10 \mathrm{mM}$ in PBS. Two $\mathrm{NH}_{4} \mathrm{Cl}_{(\mathrm{aq})}$ stock solutions at 1,000 and $2,000 \mu \mathrm{M}$ were also prepared in PBS. An appropriate amount of interferent stock and $\mathrm{NH}_{4}{ }^{+}{ }_{\text {(aq) }}$ stock were mixed to provide the desired interferent and ammonia concentrations to be tested. Amino acids and Pyr concentrations of $100,500,1,000$, and 5,000 $\mu \mathrm{M}$ were tested in combination with an ammonia concentration $\left(\left[\mathrm{NH}_{4}{ }^{+}{ }_{(\mathrm{aq})}\right]\right)$ of $30,40,150,400$, and $750 \mu \mathrm{M}$. The remaining volume was adjusted with PBS. Interferent-free ammonia QC solutions were also added to the same microplate. The synthetic analogue of bilirubin (i.e. bilirubin ditaurate (Bil)), that was used here to challenge the assay, is a mimic of bilirubin glucoronides as it shares their optical properties and water solubility ${ }^{34}$. Bil concentrations of $10,20,50$, and $100 \mu \mathrm{M}$ were used for interference challenge.

In the second interference assessment for Bil, PoSo-HPTS were used in optimized conditions to reduce Bil interference: $\mathrm{pH}_{\text {in }} 6.0, \mathrm{pH}_{\text {out }} 8.2, \varphi=40$ vol\%, [HPTS $]_{\text {in }}=2.5 \mathrm{mM}$, [HPTS $]_{\text {assay }}=$ $2.5 \mu \mathrm{M}$, and Bil concentrations of $20,100,200$ and $500 \mu \mathrm{M}$ were used.

Finally, using PoSo-hCy, a Bil concentration of $500 \mu \mathrm{M}$ was tested against a low $\mathrm{NH}_{4}{ }^{+}(\mathrm{aq})$ QC of $40 \mu \mathrm{M}$ using the following setup: $\mathrm{pH}_{\text {in }} 6.5, \mathrm{pH}_{\text {out }} 9.5, \varphi=40$ vol\%, $[\mathrm{hCy}]$ in $=250 \mu \mathrm{M}$, $[\text { Polymer }]_{\text {assay }}=1.3 \mathrm{mg} / \mathrm{mL}, 200 \mu \mathrm{L} /$ well.

\section{Data analysis}

Linear or sigmoidal analysis were performed with OriginPro ${ }^{\circledR} 2019$ (OriginLab, MA, USA). The sigmoidal regression function was a four-parameter logistic function ("logistic" function in 
OriginPro ${ }^{\circledR}$ 2019) described by the following equation (Eq. 1):

$$
y=A_{2}+\frac{A_{1}-A_{2}}{1+\left(x / x_{0}\right)^{p}}
$$

where $A_{1}$ and $A_{2}$ set the upper and lower limit of the function, respectively, $x_{0}$ is the center, and $\mathrm{p}$ is the power. The coefficient of determination was represented by the adjusted $\mathrm{R}^{2}$ (Adj. $\mathrm{R}^{2}$ ) calculated with OriginPro ${ }^{\circledR}$ 2019. Back-calculated concentrations of calibrants or QCs were determined directly using the "Find $X$ from $Y^{\prime \prime}$ feature in OriginPro ${ }^{\circledR} 2019$ (OriginLab).

In interference analysis experiments, Brown-Forsythe and Welch ANOVA (parametric; unmatched) statistical analysis was performed with Holm-Sidak's multiple comparison tests using GraphPad Prism 8.2 (GraphPad Software, CA, USA).

The number of independent experiments is denoted as $\mathrm{N}$ and the number of technical replicates is denoted as $\mathrm{n}$. The latter is also used for the number of ammonia measurements of independently prepared replicate QC solutions within one experimental run.

\section{Results and Discussion}

\section{PoSo characterization}

PoSo of PS block 3,500-4,500 kDa were used in this study since they were already found wellsuited in previous experiments ${ }^{14,35}$. The PoSo diameter distributions by laser diffraction were primarily unimodal with a main mode diameter of $3.5 \mu \mathrm{m}$ (Supplementary Figure S1).

\section{Optical properties of PoSo-HPTS}

The propensity of HPTS to self-quench was assessed (Supplementary Figure S2) and an [HPTS] in of $1 \mathrm{mM}$ was initially selected for the produced PoSo-HPTS. The optical properties of HPTS upon encapsulation into PoSo were then investigated by preparing a series of PoSoHPTS suspensions with $\mathrm{pH}_{\mathrm{in}}=\mathrm{pH}_{\text {out }}$ (Figure $\mathbf{1}$ and Supplementary Figure S3). The excitation spectra of free HPTS in buffer solutions with pH between 4.0 and 8.1 are shown in Figure 1a. As previously reported ${ }^{36}$, the HPTS fluorescence depends highly on $\mathrm{pH}$ at $\lambda_{\text {exc }}$ of $455 \mathrm{~nm}$ and $\mathrm{pH}$ above 5.7 but is $\mathrm{pH}$-independent at $\lambda_{\text {exc }}$ of $416 \mathrm{~nm}$ (isosbestic point) (Figure 1a). The corresponding spectra for PoSo-HPTS with $\mathrm{pH}_{\text {in }}=\mathrm{pH}_{\text {out }}$ as well as one case of $\mathrm{pH}_{\text {in }} \neq$ 
pHout (for comparison) are shown in Figure 1b. The isosbestic point and the $\lambda_{\text {exc }}$ of maximum $\mathrm{pH}$-dependency of HPTS remained almost unaffected by the encapsulation into PoSo (Figure 1b). Only a slight increase in the onset of the $\mathrm{pH}$-dependent behavior of HPTS (ca. $0.5 \mathrm{pH}$ units) was found for PoSo-HPTS in comparison to free HPTS, which is seen when plotting the $515 \mathrm{~nm}$ emission intensity ratios $\mathrm{I}_{455} / \mathrm{I}_{416}$ (where $\mathrm{I}_{455}$ is the dye fluorescence intensity with $\lambda_{\text {exc }}$ $455 \mathrm{~nm}, \lambda_{\mathrm{em}} 515 \mathrm{~nm}$ and $\mathrm{I}_{416}$ the dye fluorescence intensity with $\lambda_{\mathrm{exc}} 416 \mathrm{~nm}, \lambda_{\mathrm{em}} 515 \mathrm{~nm}$ ) against pH (free HPTS) or $\mathrm{pH}_{\text {in }}$ (PoSo-HPTS) (Figure 1c).

A sigmoidal dependence of the $\mathrm{I}_{455} / \mathrm{I}_{416}$ ratio as a function of $\mathrm{pH}$ was observed for both the free and PoSo-encapsulated HPTS, which is in line with the literature for free HPTS ${ }^{36}$. This dependence was well described by a four-parameter logistic model, as shown in Figure 1c. Importantly, establishing a $\mathrm{pH}$ gradient across the vesicle membrane did not affect the characteristic ratio $\mathrm{I}_{455} / \mathrm{I}_{416}$ used for $\mathrm{pH}$ sensing (Figure 1C, filled triangle vs. circle for $\mathrm{pH}$ in 5.7).

\section{Accuracy and precision of PoSo-HPTS ammonia assay}

For ammonia sensing, a higher $\mathrm{pH}_{\text {out }}$ than $\mathrm{pH}_{\text {in }}$ is necessary to achieve and sustain a concentration gradient of uncharged ammonia molecules across the vesicle membrane ${ }^{14}$. The uncharged ammonia molecules can diffuse from the outer to the inner medium, where they become protonated to ammonium and stably trapped, leading to a $\mathrm{pH}$ increase in the PoSo core until equilibrium is established ${ }^{14}$. The initial $\mathrm{pH}_{\text {in }}$ of the PoSo-HPTS should thus be close to the onset of the $\mathrm{pH}$-dependency of the sensing fluorescence ratio $\mathrm{I}_{455} / \mathrm{I}_{416}$, i.e. in the $\mathrm{pH}$ range 5.7-6.2 (Figure 1c), so that the dynamic increase of $\mathrm{pH}_{\text {in }}$ upon PoSo-HPTS incubation with an ammonia-containing sample can be directly translated into an increase of the assay signal $\mathrm{I}_{455} / \mathrm{I}_{416}$.

In a previous pilot experiment with a similar PoSo-HPTS system, $\mathrm{pH}_{\text {in }}$ of 5.7 and a $\mathrm{pH}_{\text {out }}$ of 7.4 were used, while linear regression was applied to model the ammonia sensing calibration curve $^{14}$. These conditions were also employed here for comparison (with a sample volume fraction $(\varphi)$ of 25 vol\% in the assay), and a calibration curve of excellent linearity was obtained 
(Supplementary Figure S4), as indicated by the high coefficient of determination (Adj. $\mathrm{R}^{2}$ of 0.996$)$. PBS was used as a surrogate matrix for the preparation of the calibrant solutions due to the presence of endogenous ammonia in blood plasma.

Next, it was investigated whether we could increase the slope of the calibration curve by increasing the transmembrane $\mathrm{pH}$ gradient. Therefore, we tuned the $\mathrm{pH}_{\text {out }}$ between 7.4 and 9.5 while keeping $\mathrm{pH}_{\text {in }}$ at 6.2 (Figure 2) or 5.7 (Supplementary Figure S4). Higher transmembrane $\mathrm{pH}$ gradients led indeed to calibration curves of steeper slopes for both $\mathrm{pH}_{\text {in }}$ values and hence to a wider quantitative detection range, albeit with a concomitant deterioration of linearity (Figure 2a and Supplementary Figure S4). This can be attributed to the larger influx of uncharged $\mathrm{NH}_{3}$ molecules into the PoSo core and thus the larger $\mathrm{pH}$ increase for higher $\mathrm{pH}_{\text {out, }}$ which in turn increases the $\mathrm{I}_{455} / \mathrm{I}_{416}$ ratio first within, and then beyond the linear region of the sigmoidal pH-dependency curve of this ratio (Figure 1c). A sigmoidal, four-parameter logistic fit was thus applied and was proven as an excellent regression model for the ammonia sensing calibration curves at all $\mathrm{pH}_{\text {out }}$ values tested (Figure $\mathbf{2 b}$ and

\section{Supplementary Figure S4).}

The impact of choosing a sigmoidal instead of a linear fit on the assay performance was further investigated by means of accuracy and precision. The relative error (RE) of the assaydetermined vs. nominal $\left[\mathrm{NH}_{4}{ }^{+}{ }_{(a q)}\right]$ served as a measure of accuracy, while the coefficient of variation (CV) reflected the precision (low RE and CV represent high accuracy and precision, respectively). Regarding the calibration curve itself, the guidelines on bioanalytical method validation by $\mathrm{EMA}^{24}$ and $\mathrm{FDA}^{23}$ suggest that the back-calculated calibrant concentrations should have RE within $\pm 15 \%$, except for the lower limit of quantification (LLOQ) for which RE up to $\pm 20 \%$ is acceptable, and this should hold true for at least $75 \%$ of the calibration levels. It is noted that for ligand-binding assays, which often have sigmoidal calibration curves, the corresponding RE limits by EMA are $\pm 20 \%$ or $\pm 25 \%$, while two calibration levels can be added (one below the LLOQ and one above the upper limit of quantification (ULOQ)) to serve as "anchor points" that do not require acceptance criteria. However, in Figure 2, all 8 calibration 
levels from 10 to $800 \mu \mathrm{M} \mathrm{NH}_{4}{ }^{+}$(aq) in PBS were considered as calibrants (no anchor point) and the more stringent RE limits ( \pm 15 or $\pm 20 \%$ ) were applied for both fits.

Figure $\mathbf{2 c}$ shows the fraction of the calibration levels from Figure $\mathbf{2} \mathbf{a}, \mathbf{b}$ whose mean $(\mathrm{n}=\mathbf{3}$ wells per level) back-calculated $\left[\mathrm{NH}_{4}{ }^{+}(\mathrm{aq})\right]$ complied with the aforementioned EMA criteria. When linear fit was applied, no $\mathrm{pH}_{\text {out }}$ led to more than $75 \%$ of calibration levels with acceptable accuracy (Figure 2c). On the contrary, sigmoidal fit resulted in calibration curves with $\geq 75 \%$ calibrants with acceptable accuracy for all $\mathrm{pH}_{\text {out }}$ values (Figure 2c). For the sake of clarity, Figure 2a-c shows the results for one experiment $(\mathrm{N}=1)$, though two more independent experiments (or "runs") were performed on consecutive days for all conditions. In the two new runs, acceptable accuracy was again only observed for $<75 \%$ of calibrants when using linear fit. However, using a sigmoidal fit, $>75 \%$ of calibrants showed acceptable accuracy in these new runs for all pHout except $\mathrm{pH}_{\text {out }} 7.4$ (here only $63 \%$ of calibrants had acceptable accuracy).

In every independent run, QC solutions in PBS were assessed at three $\left[\mathrm{NH}_{4}{ }^{+}{ }_{(\mathrm{aq})}\right)$ levels $(60$, 400 , and $750 \mu \mathrm{M})$, with five independently prepared replicate solutions $(n=5)$ per level. The precision and accuracy of the assay-determined $\left[\mathrm{NH}_{4}{ }^{+}(\mathrm{aq})\right]$ were compared between linear and sigmoidal fit using data from each run $(N=1)$ or from all three runs $(N=3)$ to express the within- or between-run precision and accuracy. Excellent within-run precision was obtained for both regression models in run 1 (Supplementary Table S1), and this was generally also the case for runs 2 and 3 (except for two cases with the linear fit). In terms of between-run precision (Supplementary Table S1), however, the linear fit resulted in CV $\leq 15 \%$ only for the QCs of 400 and $750 \mu \mathrm{M}$, while for the lowest QC of $60 \mu \mathrm{M}$ a CV $>15 \%$ was observed for almost all $\mathrm{pH}_{\text {out }}$ (except $\mathrm{pH}_{\text {out }}$ 8.0). The sigmoidal fit, on the other hand, led to excellent between-run precision in all cases, except for the isolated case of $60 \mu \mathrm{M} Q \mathrm{C}$ at $\mathrm{pH}_{\text {out }} 7.4$ where a CV of $17 \%$ was observed (Supplementary Table S1). The superior between-run precision with sigmoidal fitting is also illustrated in Figure 2d, where the fraction of QC levels with CV $\leq 15 \%$ is shown for run 1 (within-run precision) and runs $1-3$ (between-run precision). 
In terms of accuracy, the mean RE was often $>15 \%$ for the linear fit both within-run and between-run, in contrast to the sigmoidal fit for which RE $\leq 15 \%$ was observed in the majority of cases (Supplementary Table S1). For a better overview of the assay accuracy, Figure 2e shows the fraction of total QCs (3 levels, 5 independent replicates per level) with acceptable accuracy in run $1(\mathrm{~N}=1)$ or all three runs $(\mathrm{N}=3)$ for all $\mathrm{pH}_{\text {out }}$ values and both types of fit. These fractions are compared with a limit of $67 \%$ (dotted line in Figure $\mathbf{2 e}$ ), in accordance with the $\mathrm{EMA}^{24}$ and $\mathrm{FDA}^{23}$ guidelines. In the case of linear fit, no tested $\mathrm{pH}_{\text {out }}$ value led to $\geq 67 \%$ of total QCs with acceptable accuracy in run 1 while only for $\mathrm{pH}_{\text {out }} 8.5$ this limit was surpassed in the between-run evaluation. On the contrary, all $\mathrm{pH}_{\text {out }}$ values resulted in $\geq 67 \%$ of total QCs with acceptable accuracy for the sigmoidal fit, with the only exception being $\mathrm{pH}_{\text {out }} 7.4$ in the between-run evaluation for which a fraction of $58 \%$ was observed.

Taken together, the sigmoidal fit outperformed the linear one in respect of coefficient of determination, accuracy, and precision. Therefore, the former was used for further optimization of the ammonia assay. Regarding $\mathrm{pH}_{\text {out }}$ selection, $\mathrm{pH}_{\text {out }} 7.4$ was excluded from further studies as it yielded the lowest accuracy and precision for sigmoidal calibration curves. Furthermore, $\mathrm{pH}_{\text {out }}$ values $>8.5$ were excluded and a refinement in the range 8.0-8.5 was performed in order to maintain a high assay performance while minimizing the amplitude of the transmembrane $\mathrm{pH}$-gradient. Considering our results at $\mathrm{pH}_{\text {in }} 5.7$ and $6.2, \mathrm{pH}_{\text {in }} 6.0$ was selected for all further experiments.

Furthermore, the effect of the amount of ammonia molecules relative to PoSo on assay performance was investigated by varying the volume fraction $(\varphi)$ of the ammonia-containing sample in the assay while keeping a constant PoSo-HPTS concentration. Figure 3a shows ammonia assay calibration curves obtained with PoSo-HPTS and performed with $\varphi=10,25$, or $40 \mathrm{vol} \%$ and $\mathrm{pH}_{\text {out }} 8.0,8.2$, or 8.5 . Eleven calibration levels in the range $30-800 \mu \mathrm{M} \mathrm{NH}{ }_{4}^{+}$(aq) in PBS were used, while a $10 \mu \mathrm{M}$ standard served as anchor point. For all $\mathrm{pH}_{\text {out }}$ values, increasing $\varphi$ resulted in steeper calibration curves (and thus enhanced sensitivity) in all three independently performed experimental runs (Figure 3a shows results for run 1 ). This can be 
attributed to the increasing amount of ammonia relative to PoSo, which leads to a higher influx of uncharged $\mathrm{NH}_{3}$ into the vesicle core and thereby a larger increase in $\mathrm{pH}_{\text {in }}$ for a given $\left[\mathrm{NH}_{4}{ }^{+}{ }_{(\mathrm{aq})}\right]$ in the calibrant solutions. The Adj. $\mathrm{R}^{2}$ was $\geq 0.995$ for all calibration curves, further confirming the robustness of the four-parameter logistic model for the assay. All calibration curves of run 1 resulted in $\geq 75 \%$ of calibration levels with $R E$ of the mean back-calculated $\left[\mathrm{NH}_{4}{ }^{+}{ }_{(\mathrm{aq})}\right]$ being within $\pm 15 \%$ (or $\pm 20 \%$ for the LLOQ) (Figure $3 \mathbf{b}$ ), similarly to runs 2 and 3.

QCs prepared in PBS were used at three $\left[\mathrm{NH}_{4}{ }^{+}{ }_{(\mathrm{aq})}\right]$ levels $(45,400$, and $750 \mu \mathrm{M})$, with five independently prepared replicate solutions $(n=5)$ per level. Excellent within- and between-run precision was observed for nearly all $\varphi$ and $\mathrm{pH}_{\text {out }}$ values tested (Figure 3c and Supplementary Table S2). In terms of accuracy, a general trend of improved performance with increasing $\varphi$ from 10 to 40 vol\% was noted, especially for $\mathrm{pH}_{\text {out }} 8.0$ and 8.2 (Figure 3d and Supplementary Table S2). The highest within-run (run 1) and between-run (runs 1-3) accuracy was obtained for the combination $\varphi=40$ vol\% and $\mathrm{pH}_{\text {out }} 8.2$, which was hence selected for subsequent experiments.

To further improve assay performance, the calibration curve was extended to include an additional anchor point at $1000 \mu \mathrm{M} \mathrm{NH}_{4}{ }^{+}{ }_{(\mathrm{aq})}$, besides the already applied low anchor at $10 \mu \mathrm{M}$. This modification yielded a sensing range between 30 and $800 \mu \mathrm{M} \mathrm{NH}_{4}{ }^{+}$(aq), which is adequate for ammonia sensing in plasma, as it covers patients with normal and elevated ammonia levels ${ }^{5,7}$. To validate the assay, five $(\mathrm{N}=5)$ independent runs were performed over five consecutive days. The obtained calibration curves are shown in Supplementary Figure S5a, indicating an excellent between-run reproducibility. In all runs, the Adj. $\mathrm{R}^{2}$ was $\geq 0.999$ and $100 \%$ of the calibration levels passed the RE limits (Supplementary Figure S5), highlighting the benefit of using two anchor points. Upon QCs preparation in PBS, the EMA ${ }^{24}$ and FDA ${ }^{23}$ guidelines were followed for the selection of the $\left[\mathrm{NH}_{4}{ }^{+}{ }_{(\mathrm{aq})}\right]$ levels, namely we included a QC at the LLOQ, which should be identical to the lowest calibrant (i.e. $30 \mu \mathrm{M})$, one within three times the LLOQ (low QC, which was set to $40 \mu \mathrm{M}$ ), one at around $50 \%$ of the calibration curve range (medium QC, set to $400 \mu \mathrm{M}$ ), and one at $\geq 75 \%$ of the upper calibration curve range (high QC, 
set to $750 \mu \mathrm{M}$ ). Additionally, a QC at $150 \mu \mathrm{M}$ was used. In each level, five replicate solutions $(n=5)$ were prepared independently. As shown in Supplementary Figure S5b-c, both the within-run (run 1) and between-run (runs 1-5) accuracy and precision requirements were surpassed, as $100 \%$ of the QC replicates per level and hence $100 \%$ of the total QCs had RE and CV within $\pm 15 \%$ (or $\pm 20 \%$ for the LLOQ). As a further indication of robustness of the assay on achieving an LLOQ of $30 \mu \mathrm{M}$, the assay-determined values for all replicates of the $30 \mu \mathrm{M}$ QC are shown in Supplementary Figure S5d for run 1 and all five runs. When all runs are taken into account, the values are randomly scattered around a mean value of $31 \mu \mathrm{M}$ within the limiting RE of $\pm 20 \%$.

Overall, these data confirmed that the optimized PoSo-HPTS ammonia assay performed at a regulatory acceptable standard for ammonia quantification within 30-800 $\mu \mathrm{M}$, when assessed in PBS. The optimized PoSo-HPTS properties and assay conditions were defined as: $5.5 \mathrm{mM}$ citric acid as inner buffer at pH 6.0 and $300 \mathrm{mOsm} / \mathrm{kg}, 50 \mathrm{mM}$ borate as outer buffer at $\mathrm{pH} 8.2$ and $300 \mathrm{mOsm} / \mathrm{kg},[\text { HPTS }]_{\text {in }}=1 \mathrm{mM},[\text { HPTS }]_{\text {assay }}=0.4 \mu \mathrm{M}, \varphi=40$ vol\% with a total volume of $100 \mu \mathrm{L} /$ well in the assay plate, and four-parameter logistic fit for calibration.

\section{Interference testing}

Operating the PoSo-HPTS assay in the aforementioned optimized conditions, we then sought to investigate its performance in the presence of potential endogenous interferents. Each interferent was added at various concentrations to $\mathrm{NH}_{4}{ }^{+}$(aq) control solutions in PBS and the assay-determined mean ammonia concentrations in the presence and absence of interferent were compared.

A selection of basic (i.e. Lys), neutral nonpolar (i.e. Met), and hydrophobic, styrene-like (i.e. Phe) amino acids were assessed for interference. These amino acids were tested in a broad concentration range that spanned below and above their physiological plasmatic levels ${ }^{26}$. Statistically non-significant $(n s)$ differences $(p>0.05)$ between samples with and without amino acids were obtained, indicating that all three amino acids do not interfere with the assay (Figure 4a and Supplementary Figure S6). This is consistent with a previous 
work which used a similar PoSo-HPTS assay that also showed to be selective towards ammonia in the presence of a variety of amino acids and other amine-containing molecules ${ }^{14}$.

Pyr was included in the interference study as it is a common interferent for enzymatic ammonia assays ${ }^{27}$. The employed concentration range in this case embraced the threshold value of $750 \mu \mathrm{M}$, which is reported by several manufacturers of enzymatic, in vitro diagnostic tests for ammonia (e.g. Ammonia ${\mathrm{L} 3 \mathrm{~K}^{\circledR}}^{\circledR}$ Assay (Sekisui Diagnostics), Infinity ${ }^{\mathrm{TM}}$ Ammonia Reagent (Fisher Diagnostics/Beckman Coulter Inc.), or Ammonia Ultra (SENTINEL CH. SpA/Abbott Laboratories Inc. )) as the maximum plasma Pyr concentration for no interference. As expected, Pyr did not interfere with the assay even at concentrations as high as 5,000 $\mu \mathrm{M}$ (Figure 4b and Supplementary Figure S6).

Bil was also tested since bioanalytical assays developed for blood or plasma are desired to cope with values of bilirubin at least up to $500 \mu \mathrm{M}^{28}$, which accounts for the potentially elevated bilirubin levels in the plasma of patients with liver diseases ${ }^{37}$. However, Bil interfered with the ammonia measurements at all challenge concentrations (Figure 4c and Supplementary Figure S6). This interference of $\mathrm{Bil}$ can be attributed to the overlap between the Bil absorbance spectrum and the PoSo-HPTS fluorescence spectra (Figure 5a).

We therefore tried to reduce the optical interference of Bil in the PoSo-HPTS assay by increasing the [HPTS $]_{\text {assay. }}$ An increased total HPTS concentration in the produced batches was thus required, and to achieve this, various process parameters including the [HPTS] in as well as the injected polymer solution volume during PoSo preparation were tuned. It was found that the most effective reduction of Bil interference could be achieved using a PoSo-HPTS batch with a $[\text { HPTS }]_{\text {in }}=2.5 \mathrm{mM}$ (instead of $1 \mathrm{mM}$ ) and tested with a $[\text { HPTS }]_{\text {assay }}=2.5 \mu \mathrm{M}$ (instead of $0.4 \mu \mathrm{M}$ ), keeping all other conditions unchanged (i.e. $\mathrm{pH}_{\text {in }} 6.0, \mathrm{pH}_{\text {out }} 8.2, \varphi=$ 40 vol\%). It is noted that also with these modified PoSo-HPTS, $100 \%$ of calibrants and QCs fulfilled the required accuracy and precision criteria for ammonia quantification in aqueous buffers (no interferent present) (Supplementary Figure S7). 
The $\left[\mathrm{NH}_{4}{ }^{+}{ }_{(\mathrm{aq})}\right]$ measured with the modified PoSo-HPTS assay in the presence of various Bil concentrations is shown in Figure $\mathbf{5 b}, \mathbf{c}$. The higher [HPTS] assay and thus HPTS signal in the new setup alleviated the interference of bilirubin, and the assay could retrieve the nominal $\left[\mathrm{NH}_{4}{ }^{+}{ }_{(\mathrm{aq})}\right]$ accurately for [Bil] up to at least $20 \mu \mathrm{M}$. At [Bil] of $100 \mu \mathrm{M}$ or higher, however, Bil started interfering again with the assay. With this level of tolerance for Bil, our assay using PoSo-HPTS is in principle appropriate for $\mathrm{NH}_{4}{ }^{+}$(aq) measurements in healthy human plasma (physiological bilirubin concentrations up to $\sim 20 \mu \mathrm{M}^{38}$ ) and in plasma samples of individuals with slightly elevated bilirubin levels.

\section{PoSo-HPTS assay for ammonia measurements in human plasma}

The PoSo-HPTS assay using the improved conditions from Figure $\mathbf{5}$ was applied for ammonia quantification in human plasma and its performance was compared to the PocketChem Blood Ammonia Analyzer, an in vitro diagnostics POC device that uses colorimetric detection of alkalized ammonia via microdiffusion on a strip ${ }^{39}$. Figure $6 \mathbf{a}$ shows the ammonia sensing calibration curves of the PoSo-HPTS assay obtained with calibrant solutions prepared either in PBS or in (ammonia-spiked) healthy human plasma. Both calibration curves had an excellent coefficient of determination and were used to determine the total $\left[\mathrm{NH}_{4}{ }_{(\mathrm{aq})}\right]$ in a healthy human plasma sample before and after spiking it with various concentrations of $\mathrm{NH}_{4}{ }^{+}$(aq) (Figure 6b). For spiked $\left[\mathrm{NH}_{4}{ }_{(\mathrm{aq})}\right]$ up to $120 \mu \mathrm{M}$, the measured ammonia concentrations from the PoSoHPTS assay (using either calibration curve) were comparable to the values received with the POC device (Figure 6b), with a maximum RE of $-26 \%$ for the PoSo-HPTS assay on the unspiked plasma sample and a minimum RE of $-8 \%$ for the assay on the $120 \mu \mathrm{M} \mathrm{NH}_{4}{ }^{+}$(aq)spiked plasma sample (Supplementary Table S3). It is noted that due to the relatively low ULOQ of the POC device (reportedly $286 \mu \mathrm{M}$ ), this method could not be used on $\mathrm{NH}_{4}{ }^{+}$(aq)spiked plasma samples examined in this experiment above this range (Figure 6b).

The PoSo-HPTS assay with calibrants in PBS resulted generally in lower measured $\left[\mathrm{NH}_{4}{ }^{+}{ }_{(\mathrm{aq})}\right]$ values than that with calibrants in plasma, with the RE increasing for increasing spiked $\left[\mathrm{NH}_{4}{ }_{(\mathrm{aq})}\right]$ (Figure 6b and Supplementary Table S3). This can be explained by the observed 
concentration-dependent deviation between the two calibration curves (Figure 6a), which suggests the presence of some matrix effects when PBS is used as calibration medium ${ }^{40}$. Nevertheless, the RE on the $\left[\mathrm{NH}_{4}{ }^{+}{ }_{(\mathrm{aq})}\right]$ determined by the calibration curve in PBS $v s$. the one in plasma was lower than 25\% (Figure 6a), and hence PBS could be a reasonable surrogate matrix for plasma. This is also confirmed when considering the retrieved spiked $\left[\mathrm{NH}_{4}{ }^{+}{ }_{\text {(aq) }}\right]$ (Figure 6c), for which a high accuracy (RE $\leq 25 \%$ ) was obtained for the PoSo-HPTS assay using either calibration curve (i.e. whether calibrants were prepared in plasma or PBS). The retrieved spiked $\left[\mathrm{NH}_{4}{ }_{(}{ }_{(\mathrm{aq})}\right]$ values from the PoSo-HPTS assay compared well with the data obtained with the POC device (Figure 6c).

\section{Alternative fluorescent dye to overcome bilirubin interference}

To overcome the interference from bilirubin, we sought a water-soluble, $\mathrm{pH}$-sensitive, ratiometric fluorophore that absorbs and emits above $550 \mathrm{~nm}$. In terms of optical properties, a molecular dye with excitation and emission in the second near-infrared window (NIR-II) $(1000-1700 \mathrm{~nm})^{41}$ would be ideal for increasing the signal to noise ratio in plasma and even working with blood samples. NIR-II fluorophores, however, show an important drop of quantum yield in the presence of water, as they are generally very hydrophobic and have not been made $\mathrm{pH}$-sensitive to our knowledge ${ }^{41}$.

Among the commercially available, ratiometric, $\mathrm{pH}$-sensitive fluorophores with excitation/emission wavelengths longer than those of HPTS, a rhodamine derivative (SNARF ${ }^{\mathrm{TM}}$ 4F) was the first one to be tested here (Supplementary Figure S8). Upon excitation at $\lambda_{\text {exc }}$ $=515 \mathrm{~nm}, \mathrm{SNARF}^{\mathrm{TM}}-4 \mathrm{~F}$ exhibits an isoemissive point at $\lambda_{\mathrm{em}}=635 \mathrm{~nm}$ and a $\mathrm{pH}$-dependent emission peak at $\lambda_{\mathrm{em}}=660 \mathrm{~nm}$ (Supplementary Figure S8). However, the SNARF ${ }^{\mathrm{TM}}-4 \mathrm{~F}$ fluorescence and $\mathrm{pH}$ sensitivity were largely affected by the encapsulation into PoSo (Supplementary Figure S8). This effect was attributed to a shift of the equilibrium towards the lactone which, in equilibrium with the protonated SNARF ${ }^{\mathrm{TM}}-4 \mathrm{~F}$, is devoid of absorbance in the visible region (the cyclization breaks the $n$ network) ${ }^{42,43}$. The lactone is favored by apolar aprotic milieu ${ }^{42}$, hence the altered fluorescence properties upon encapsulation may be an 
indication of SNARF ${ }^{\mathrm{TM}}-4 \mathrm{~F}$ partitioning in the PS- $b$-PEG bilayer. Apart from being extensively characterized for fluorophores in the bulk ${ }^{44}$, such alterations of optical properties have been reported upon interaction of ( $\mathrm{pH}$-sensitive) fluorophores with other membrane bilayers, such as in liposomes ${ }^{45,46}$.

Wan et al. ${ }^{33}$ reported on a pH-sensitive hemicyanine fluorophore (Lyso-pH) that exhibits an isoemissive point at $\lambda_{\mathrm{em}}=670 \mathrm{~nm}$ and an emission peak of maximum $\mathrm{pH}$-dependency at $\lambda_{\mathrm{em}}=708 \mathrm{~nm}\left(\lambda_{\mathrm{exc}}=635 \mathrm{~nm}\right)$. This dye was evaluated next and PoSo-Lyso were produced (Supplementary Figure S9). PoSo-Lyso also exhibited pH-dependency in emission, though in a different $\mathrm{pH}$ range $(\mathrm{pH} 2-6.5)$ compared to the free Lyso-pH ( $\mathrm{pH} 4-7.5)$ (Supplementary Figure 59). Considering the relatively low hydrophilicity of Lyso-pH, this hints to a possible partitioning ${ }^{45,47}$ and/or non-covalent interactions ${ }^{48,49}$ of the dye with the polymeric bilayer,

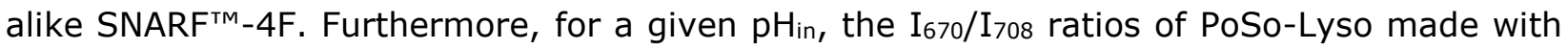
$\mathrm{pH}_{\text {out }}>\mathrm{pH}_{\text {in }}$ were lower than those of PoSo-Lyso made with $\mathrm{pH}_{\mathrm{in}}=\mathrm{pH}_{\text {out }}$, which could indicate non-specific binding of the dye to the vesicle membrane and/or dye leakage to the outer PoSo medium. The incorporation of the surfactant SDS in the encapsulated Lyso-pH solution upon PoSo preparation minimized this effect (Supplementary Figure S9), but the increased complexity of the system led us to set aside this approach.

Finally, a hemicyanine dye (hCy) that was reported by Yuan et al. ${ }^{32}$ (Figure 7a) had the desired characteristics, and was selected to produce PoSo-hCy for the ammonia assay. The pH-dependency and optical properties of hCy are illustrated in Figure 7b-c. In absorbance, it exhibits an isosbestic point at $\sim 620 \mathrm{~nm}$ (Figure 7b), while an isoemissive point (at $\sim 668 \mathrm{~nm}$ ) and a wavelength of maximum pH-dependency (at $\sim 707 \mathrm{~nm}$ ) are observed in its fluorescence emission spectra (Figure 7c). Plotting the fluorescence ratio $\mathrm{I}_{707} / \mathrm{I}_{668}$ as a function of $\mathrm{pH}$ (Figure 7d) revealed a sigmoidal pH-dependency at $\mathrm{pH}$ above 6.5.

After an initial optimization process, PoSo-hCy for the ammonia assay were made with a $\mathrm{pH}_{\text {in }}$ of 6.5 and $\mathrm{a} \mathrm{pH}_{\text {out }}$ of 9.5, while the fluorescence measurements in the assay were performed at $\lambda_{\mathrm{em}}=682 \mathrm{~nm}$ and $712 \mathrm{~nm}$ for $\lambda_{\mathrm{exc}}=630 \mathrm{~nm}$. The employed wavelengths were 
slightly modified compared to the aforementioned characteristic wavelengths of free hCy, due to the slight shift of the fluorophore's optical properties after its encapsulation into the vesicles. Furthermore, PoSo-hCy ammonia assays were performed with an incubation time of 5 min to minimize well-to-well cross-talk that was observed when longer incubation times and/or a pHout of 10 were used (Supplementary Figure S10). This cross-talk was attributed to an interference from wells containing solutions of high $\left[\mathrm{NH}_{4}{ }^{+}(\mathrm{aq})\right]$ to neighboring wells of relatively low $\left[\mathrm{NH}_{4}{ }_{(\mathrm{aq})}\right]$, due to ammonia evaporation from the former and recondensation in the latter $\left(\mathrm{pKa} \mathrm{NH}_{4}{ }^{+} / \mathrm{NH}_{3}=9.2\right)$.

Performing the PoSo-hCy ammonia assay with calibrant solutions in PBS, a sigmoidal calibration curve with an excellent coefficient of determination was obtained (Supplementary Figure S11). The $\left[\mathrm{NH}_{4}^{+}{ }_{(\mathrm{aq})}\right]$ measured for the low $\mathrm{QC}$ using the calibration curve from Supplementary Figure $\mathbf{S 1 1}$ in solutions containing various concentrations of Bil is shown in Figure 8a, confirming the expected absence of Bil interference when hCy is the assay's fluorescence reporter. In fact, Bil did not interfere with the assay even with Bil concentrations as high as $500 \mu \mathrm{M}$ (Figure 8a), which would in principle allow the quantification of ammonia in plasma samples of patients with liver diseases ${ }^{5,7}$.

The PoSo-hCy ammonia assay was then applied for ammonia quantification in healthy human plasma samples (unspiked and ammonia-spiked) and was compared to the POC device in two independent experiments (Figure 8b). The majority of the ammonia concentrations that were measured with the PoSo-hCy assay were comparable with those obtained with the POC device (Supplementary Table S4), though a slightly higher deviation among independent experiments was observed for the former. Furthermore, the retrieved spiked $\left[\mathrm{NH}_{4}{ }^{+}\right.$(aq) $]$from the PoSo-hCy assay were highly accurate, with $\mathrm{RE} \leq 25 \%$ for $83 \%$ (or 10 out of 12) data points, comparing well with the POC device (Figure 8c). Taken together, the use of hCy as an alternative fluorophore for the PoSo-based ammonia assay allowed us to eliminate the interference of Bil while maintaining a high performance in terms of ammonia quantification in a complex biological matrix such as plasma. 


\section{Conclusion}

In this work, we developed an analytical assay for the quantification of ammonia in blood plasma. The technology, based on transmembrane $\mathrm{pH}$-gradient PoSo, represents a promising alternative to existing ammonia quantification tests and circumvents part of the limitations commonly encountered in other strategies, such as Pyr interference. Interestingly, the assay presented some of the characteristics of a chromatographic assay and some of a ligandbinding assay, albeit not falling under either category. The use of a four-parameter logistic fitting (similarly to ligand-binding assays) allowed to widen the quantification range to 30$800 \mu \mathrm{M}$ in surrogate PBS. The assay was further refined to a working range of $40-800 \mu \mathrm{M}$ in presence of up to $500 \mu \mathrm{M} \mathrm{Bil,} \mathrm{with} \mathrm{the} \mathrm{lower} \mathrm{limit} \mathrm{of} \mathrm{the} \mathrm{range} \mathrm{being} \mathrm{still} \mathrm{below} \mathrm{the} \mathrm{higher} \mathrm{end}$ of ammonia levels found in healthy patients. Finally, in human plasma, the assay showed equivalent performance to a gold standard POC device while outperforming the ammonia quantification range of the latter in highly concentrated samples. Throughout process development, the assay was tested and confirmed to comply with regulatory standards to ensure a realistic end product. The PoSo-based ammonia assay herein was shown in a 96-well plate format, suitable for high throughput analysis. Nevertheless, the technology may be converted to provide POC practicality in the future.

\section{References}

1. Shalimar et al. Prognostic role of ammonia in patients with cirrhosis. Hepatology 70, 982-994 (2019).

2. SOS Kanto Study Group. Initial blood ammonia level is a useful prognostication tool in out-of-hospital cardiac arrest - Multicenter prospective study (SOS-KANTO 2012 study). Circ. J. 81, 1839-1845 (2017).

3. Mallet, M., Weiss, N., Thabut, D. \& Rudler, M. Why and when to measure ammonemia in cirrhosis? Clin. Res. Hepatol. Gastroenterol. 42, 505-511 (2018).

4. Walker, V. Ammonia metabolism and hyperammonemic disorders. Adv. Clin. Chem. 67, 73-150 (2014).

5. Häberle, J. Clinical and biochemical aspects of primary and secondary hyperammonemic disorders. Arch. Biochem. Biophys. 536, 101-108 (2013).

6. Matoori, S. \& Leroux, J. C. Recent advances in the treatment of hyperammonemia. Adv. Drug Deliver. Rev. 90, 55-68 (2015).

7. Chow, S. L. et al. The significance of a high plasma ammonia value. Arch. Dis. Child. 89, 585-586 (2004). 
8. Vilstrup, H. et al. Hepatic encephalopathy in chronic liver disease: 2014 Practice Guideline by the American Association for the Study Of Liver Diseases and the European Association for the Study of the Liver. Hepatology 60, 715-735 (2014).

9. Lauridsen, M. M. \& Vilstrup, H. Impact and diagnosis of minimal or grade 1 hepatic encephalopathy in Diagnosis and Management of Hepatic Encephalopathy (ed. Bajaj, J. S.) 47-64 (Springer, 2018).

10. Bajaj, J. S. et al. Important unresolved questions in the management of hepatic encephalopathy: an ISHEN consensus. Am. J. Gastroenterol. 115, 989-1002 (2020).

11. $\mathrm{Yu}, \mathrm{Q}$. Y. et al. Semisynthetic sensor proteins enable metabolic assays at the point of care. Science 361, 1122-1125 (2018).

12. Ly, T. N. \& Park, S. Highly sensitive ammonia sensor for diagnostic purpose using reduced graphene oxide and conductive polymer. Sci. Rep. 8, 18030 (2018).

13. Smith, N. L., Hong, Z. M. \& Asher, S. A. Responsive ionic liquid-polymer 2D photonic crystal gas sensors. Analyst 139, 6379-6386 (2014).

14. Matoori, S. et al. An Investigation of PS-b-PEO Polymersomes for the oral treatment and diagnosis of hyperammonemia. Small 15, 1902347 (2019).

15. Barsotti, R. J. Measurement of ammonia in blood. J. Pediatr. 138, S11-S19 (2001).

16. Tovichien, P., Luenee, P., Tientadakul, P. \& Vatanavicharn, N. Accuracy of a point-ofcare ammonia analyzer for screening of blood ammonia in pediatric patients with inborn error of metabolism. Southeast Asian J. Trop. Med. Public Health 48, 133-140 (2017).

17. Lee, J. S. et al. Circulation kinetics and biodistribution of dual-labeled polymersomes with modulated surface charge in tumor-bearing mice: Comparison with stealth liposomes. J. Control. Release 155, 282-288 (2011).

18. Ruiz-Perez, L., Hurley, C., Tomas, S. \& Battaglia, G. Separating extreme pH gradients using amphiphilic copolymer membranes. ChemPhysChem 19, 1987-1989 (2018).

19. Rideau, E., Dimova, R., Schwille, P., Wurm, F. R. \& Landfester, K. Liposomes and polymersomes: a comparative review towards cell mimicking. Chem. Soc. Rev. 47, 8572-8610 (2018).

20. Le Meins, J. F., Sandre, O. \& Lecommandoux, S. Recent trends in the tuning of polymersomes' membrane properties. Eur. Phys. J. E 34, 14 (2011).

21. Giacalone, G. et al. Liposome-supported peritoneal dialysis in the treatment of severe hyperammonemia: An investigation on potential interactions. J. Control. Release 278, 57-65 (2018).

22. Chakrabarti, A. C., Clarklewis, I., Harrigan, P. R. \& Cullis, P. R. Uptake of basic amino acids and peptides into liposomes in response to transmembrane $\mathrm{pH}$ gradients. Biophys. J. 61, 228-234 (1992).

23. U.S. FDA: Department of Health and Human Services, Center for Drug Evaluation and Research (CDER), Center of Veterinary Medicine (CVM). Bioanalytical method validation: guidance for industry (2018).

24. EMA: Committee for Medicinal Products for Human Use (CHMP). Guideline on bioanalytical method validation (2011).

25. Kadian, N. et al. Comparative assessment of bioanalytical method validation guidelines for pharmaceutical industry. J. Pharmaceut. Biomed. Anal. 126, 83-97 (2016).

26. Schmidt, J. A. et al. Plasma concentrations and intakes of amino acids in male meateaters, fish-eaters, vegetarians and vegans: a cross-sectional analysis in the EPICOxford cohort. Eur. J. Clin. Nutr. 70, 306-312 (2016).

27. Huizenga, J. R., Tangerman, A. \& Gips, C. H. Determination of ammonia in biological fluids. Ann. Clin. Biochem. 31, 529-543 (1994).

28. Dimeski, G. Interference testing. Clin. Biochem. Rev. 29 Suppl 1, S43-48 (2008).

29. Wang, S. S. et al. Synthesis of hemoglobin conjugated polymeric micelle: A ZnPc carrier with oxygen self-compensating ability for photodynamic therapy. Biomacromolecules 16, 2693-2700 (2015). 
30. Yassin, M. A., Appelhans, D., Mendes, R. G., Rummeli, M. H. \& Voit, B. pH-Dependent release of doxorubicin from fast photo-cross-linkable polymersomes based on benzophenone units. Chem. Eur. J. 18, 12227-12231 (2012).

31. Yildiz, M. E., Prud'homme, R. K., Robb, I. \& Adamson, D. H. Formation and characterization of polymersomes made by a solvent injection method. Polym. Adv. Technol. 18, 427-432 (2007).

32. Yuan, L. et al. A unique approach to development of near-infrared fluorescent sensors for in vivo imaging. J. Am. Chem. Soc. 134, 13510-13523 (2012).

33. Wan, Q. Q., Chen, S. M., Shi, W., Li, L. H. \& Ma, H. M. Lysosomal pH rise during heat shock monitored by a lysosome-targeting near-infrared ratiometric fluorescent probe. Angew. Chem. Int. Edit. 53, 10916-10920 (2014).

34. Steen, G., Klerk, A., van der Laan, K. \& Eppens, E. F. Evaluation of the interference due to haemoglobin, bilirubin and lipids on Immulite 2500 assays: a practical approach. Ann. Clin. Biochem. 48, 170-175 (2011).

35. Leroux, J.-C., Matoori, S. \& Wuerthinger, O. V. Transmembrane pH-gradient polymersomes for the quantification of ammonia in body fluids. WO 2019/053578 (2019).

36. Straubinger, R. M., Papahadjopoulos, D. \& Hong, K. Endocytosis and intracellular fate of liposomes using pyranine as a probe. Biochemistry 29, 4929-4939 (1990).

37. Peeraphatdit, T., Kamath, P. S. \& Leise, M. D. Latest concepts in inpatient hepatic encephalopathy management in Diagnosis and Management of Hepatic Encephalopathy (ed. Bajaj, J. S.) 77-97 (Springer, 2018).

38. Morgan, T. R. Management of alcoholic hepatitis. Gastroenterology and Hepatology 3, 97-99 (2007).

39. Goggs, R. et al. Clinical investigation of a point-of-care blood ammonia analyzer. Vet. Clin. Pathol. 37, 198-206 (2008).

40. Jones, B. R., Schultz, G. A., Eckstein, J. A. \& Ackermann, B. L. Surrogate matrix and surrogate analyte approaches for definitive quantitation of endogenous biomolecules. Bioanalysis 4, 2343-2356 (2012).

41. Xu, P. F. et al. Molecular engineering of a high quantum yield NIR-II molecular fluorophore with aggregation-induced emission (AIE) characteristics for in vivo imaging. Nanoscale 12, 5084-5090 (2020).

42. Marcotte, N. \& Brouwer, A. M. Carboxy SNARF-4F as a fluorescent pH probe for ensemble and fluorescence correlation spectroscopies. J. Phys. Chem. B 109, 11819-11828 (2005).

43. Seksek, O., Henrytoulme, N., Sureau, F. \& Bolard, J. SNARF-1 as an intracellular pH indicator in laser microspectrofluorometry: a critical assessment. Anal. Biochem. 193, 49-54 (1991).

44. Reichardt, C. Solvatochromic dyes as empirical indicators of solvent polarity. Chimia 45, 322-324 (1991).

45. Vecer, J., Holoubek, A. \& Sigler, K. Fluorescence behavior of the $\mathrm{pH}$-sensitive probe carboxy SNARF-1 in suspension of liposomes. Photochem. Photobiol. 74, 8-13 (2001).

46. Doval, D. A. \& Matile, S. Increasingly twisted push-pull oligothiophenes and their planarization in confined space. Org. Biomol. Chem. 11, 7467-7471 (2013).

47. Chen, Y. C., Ostafin, A. \& Mizukami, H. Synthesis and characterization of $\mathrm{pH}$ sensitive carboxySNARF-1 nanoreactors. Nanotechnology 21 (2010).

48. Xie, X. J., Zhai, J. Y., Jarolimova, Z. \& Bakker, E. Determination of $\mathrm{pK}_{a}$ values of hydrophobic colorimetric pH sensitive probes in nanospheres. Anal. Chem. 88, 30153018 (2016).

49. Barooah, N., Mohanty, J., Pal, H. \& Bhasikuttan, A. C. Non-covalent interactions of coumarin dyes with cucurbit[7]uril macrocycle: modulation of ICT to TICT state conversion. Org. Biomol. Chem. 10, 5055-5062 (2012). 


\section{Acknowledgments}

Innosuisse (grant 27072.2 PFLS-LS) and Versantis AG are acknowledged for their financial support. We thank Martina Villano for her early experimental contribution to the project, Dr. Meriam Kabbaj, Dr. Vincent Forster, and Dr. Simon Matoori for our fruitful discussions and their support throughout the project, and Dr. Lorine Brülisauer for proof-reading the manuscript.

\section{Author contributions}

The original idea was developed by $\mathrm{JCL}$ and further evolved through collaborative work with CG and AS. CG, AS, and JCL wrote the manuscript. CG, AS, LH, and JM performed the experiments as well as acquired and analyzed the data. All authors reviewed and agreed on the final manuscript.

\section{Declaration of conflict of interest}

JCL is a cofounder and shareholder of Versantis AG. LH is now an employee of Versantis AG. All other coauthors do not have any conflict of interest. 


\section{Figures}
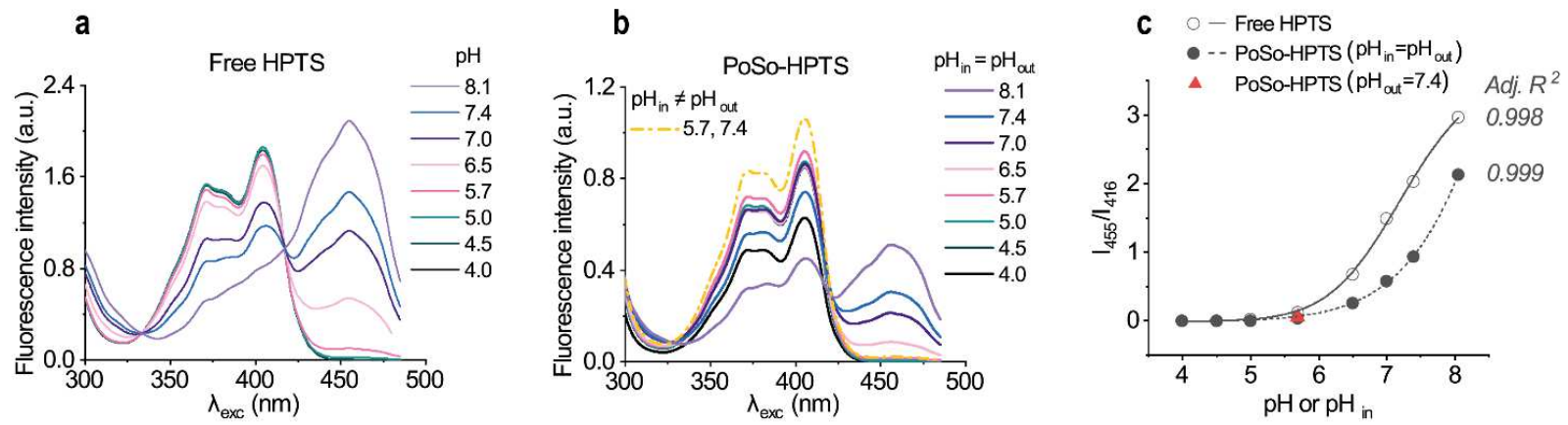

Figure 1. Fluorescence properties of free HPTS vs. PoSo-HPTS. a-b) Fluorescence excitation spectra (for $\lambda_{\mathrm{em}} 515 \mathrm{~nm}$ ) of free HPTS (a) and PoSo-HPTS (b) with $\mathrm{pH}_{\text {in }}=\mathrm{pH}_{\text {out }}$ (solid lines) and one sample with $\mathrm{pH}_{\mathrm{in}} \neq \mathrm{pH}_{\text {out }}$ (dash-dotted line) for comparison. c) Fluorescence intensity ratio $\mathrm{I}_{455} / \mathrm{I}_{416}$ at $\lambda_{\mathrm{em}} 515 \mathrm{~nm}$ (i.e. for $\lambda_{\mathrm{exc}} 455$ and $416 \mathrm{~nm}$ ) for free HPTS and PoSoHPTS (symbols) against $\mathrm{pH}$ or $\mathrm{pH}_{\mathrm{in}}$, respectively. Lines correspond to four-parameter logistic regressions. 

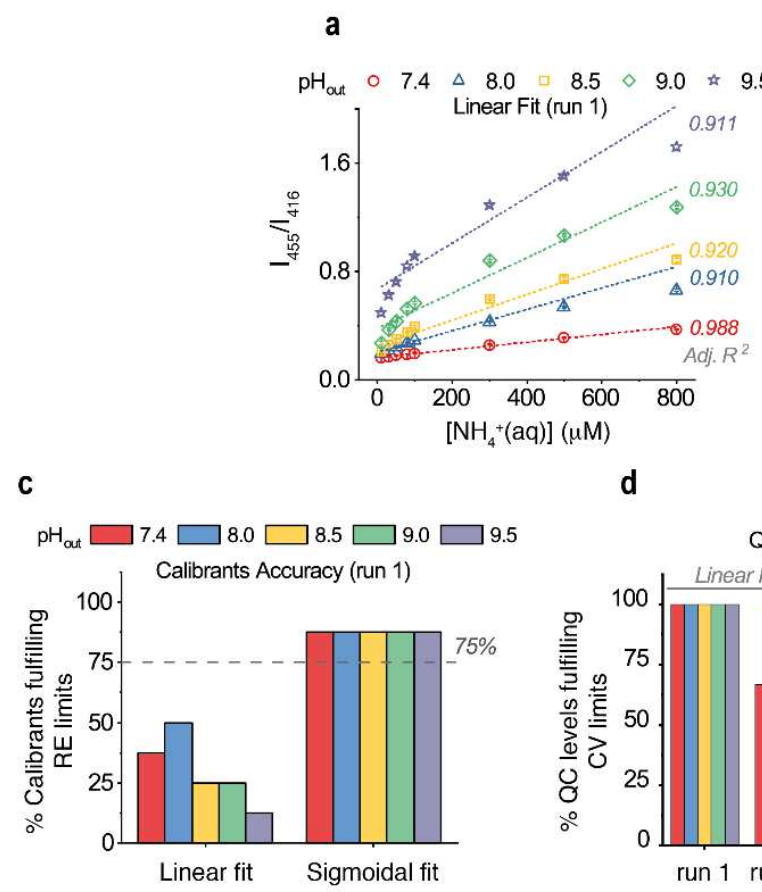

b

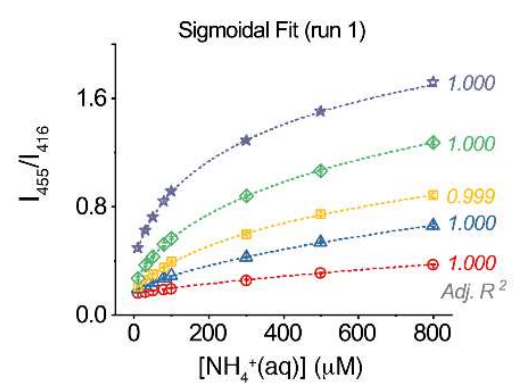

d

e
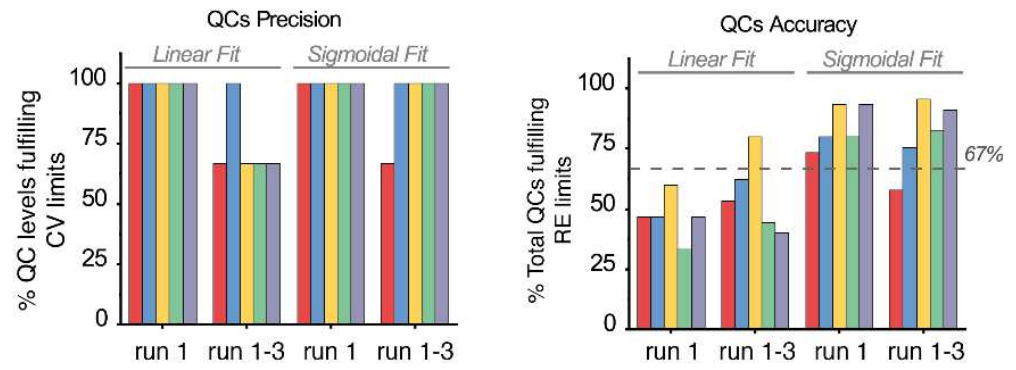

Figure 2. Performance of regression, accuracy, and precision of the PoSo-HPTS ammonia assay using varying pHout. a-b) Measured fluorescence intensity ratios $\mathrm{I}_{455} / \mathrm{I}_{416}$ $\left(\lambda_{\text {em }}=515 \mathrm{~nm}\right)$ (symbols) as a function of $\left[\mathrm{NH}_{4}{ }^{+}{ }_{(\mathrm{aq})}\right]$ in calibrant solutions (10-800 $\mu \mathrm{M}$ in PBS) using PoSo-HPTS with $\mathrm{pH}_{\mathrm{in}} 6.2$ and various $\mathrm{pH}_{\text {out }}$. Calibration curves and coefficients of determination (Adj. $R^{2}$ ) were obtained with either linear (a) or sigmoidal (b) regression. For each $\mathrm{pH}_{\text {out, }}$ results are presented as mean $\pm S D(n=3)$ of replicate wells from one experimental run (run 1). In total three independent runs were performed (runs 1, 2, and 3). Conditions: $[\text { HPTS }]_{\text {in }}=1 \mathrm{mM},[\text { HPTS }]_{\text {assay }}=0.4 \mu \mathrm{M}, \varphi=25 \mathrm{vol} \%$. c) Fraction of calibration levels from $(\mathrm{a}, \mathrm{b})$ with mean back-calculated $\left[\mathrm{NH}_{4}{ }^{+}{ }_{(\mathrm{aq})}\right]$ having $\mathrm{RE}$ within $\pm 15 \%$ (or $\pm 20 \%$ for LLOQ). Dotted line indicates the minimum acceptable fraction according to EMA ${ }^{24}$ and FDA ${ }^{23}$. d) Fraction of QC levels $\left(60,400\right.$, and $750 \mu \mathrm{M} \mathrm{NH}_{4}{ }^{+}{ }_{\text {aq }}$ in PBS; $\mathrm{n}=5$ independent replicates per level) with assay-determined $\left[\mathrm{NH}_{4}{ }^{+}{ }_{(\mathrm{aq})}\right]$ having $\mathrm{CV}$ within $\pm 15 \%$. e) Fraction of total QCs (3 levels, $\mathrm{n}=5$ independent replicates per level) with assay-determined $\left[\mathrm{NH}_{4}{ }_{(}{ }_{(a q)}\right]$ having $\mathrm{RE}$ within $\pm 15 \%$. Dotted line in (e) indicates the minimum acceptable fraction according to EMA ${ }^{24}$ and FDA $^{23}$. 

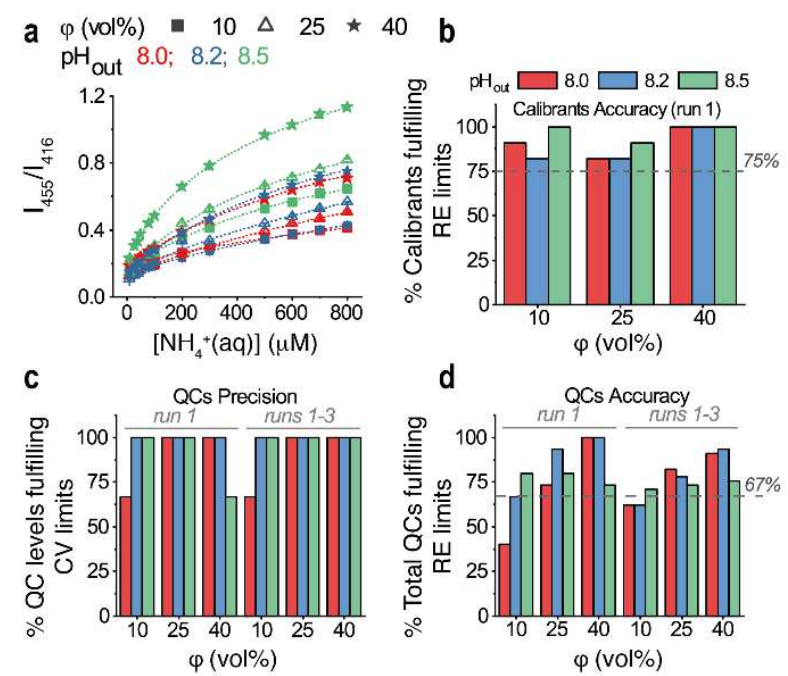

Figure 3. PoSo-HPTS calibration curves and assay performance for varying $\varphi$ and pHout. a) Ammonia sensing calibration curves obtained with sigmoidal regression fit of the measured fluorescence intensity ratio $\mathrm{I}_{455} / \mathrm{I}_{416}\left(\lambda_{e m}=515 \mathrm{~nm}\right)$ data plotted over $\left[\mathrm{NH}_{4}{ }_{(a q)}\right]$ in the calibrant solutions. Assay was performed at various $\varphi$ and $\mathrm{pH}$ out values using PoSo-HPTS. Eleven calibration levels within $30-800 \mu \mathrm{M} \mathrm{NH}_{4}{ }^{+}$(aq) in PBS were used, while a $10 \mu \mathrm{M}$ standard served as anchor point. For each condition, results are presented as mean $\pm S D(n=3)$ of replicate wells from one experimental run (run 1); error bars may be smaller than symbols. In total three independent runs were performed (runs 1, 2, and 3). Conditions: $\mathrm{pH}_{\text {in }} 6.0$, [HPTS $_{\text {in }}=1 \mathrm{mM}$, [HPTS $]_{\text {assay }}=0.4 \mu \mathrm{M}$. b) Fraction of calibration levels from (a) with mean back-calculated $\left[\mathrm{NH}_{4}{ }^{+}{ }_{(\mathrm{aq})}\right]$ having $\mathrm{RE}$ within $\pm 15 \%$ (or $\pm 20 \%$ for LLOQ). Dotted line indicates the minimum acceptable fraction according to $\mathrm{EMA}^{24}$ and $\mathrm{FDA}^{23}$. c) Fraction of independently prepared QC replicates $(n=5)$ per level $\left(45,400\right.$, and $750 \mu \mathrm{M} \mathrm{NH}_{4}{ }^{+}{ }_{\text {(aq) }}$ in PBS; corresponding to $\varphi=10,25$, and 40 vol\%, respectively) with assay-determined $\left[\mathrm{NH}_{4}{ }^{+}{ }_{(a q)}\right]$ having $\mathrm{CV}$ within $\pm 15 \%$ (or $\pm 20 \%$ for the lowest QC). d) Fraction of total QCs (3 levels, $n=5$ independent replicates per level) with assay-determined $\left[\mathrm{NH}_{4}{ }^{+}{ }_{(\mathrm{aq})}\right]$ having $\mathrm{RE}$ within $\pm 15 \%$ (or $\pm 20 \%$ for the lowest QC). Dotted line in (d) indicates the minimum acceptable fraction in accordance with $\mathrm{EMA}^{24}$ and FDA ${ }^{23}$. 


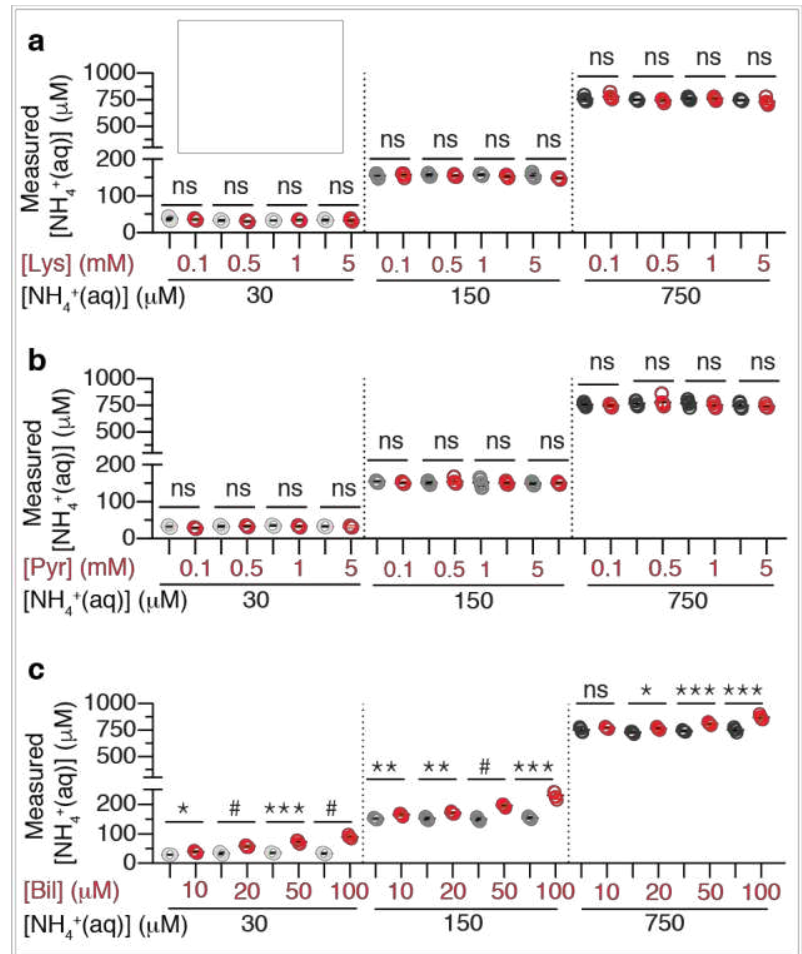

Figure 4. Analytical selectivity screening. Measured $\left[\mathrm{NH}_{4}{ }_{(\mathrm{aq})}\right]$ in the absence (grey scale symbols) and presence (red symbols) of Lys (a), Pyr (b), and Bil (c) at various concentrations in solutions containing 30, 150, or $750 \mu \mathrm{M}$ of $\mathrm{NH}_{4}{ }^{+}$(aq) in PBS. Results are shown as exact measured values and mean \pm SD ( $n=5$ independently prepared QC replicates with or without interferent). Conditions: $\mathrm{pH}_{\text {in }} 6.0, \mathrm{pH}_{\text {out }} 8.2, \varphi=40$ vol\%, [HPTS $]_{\text {in }}=1 \mathrm{mM},[\text { HPTS }]_{\text {assay }}=$ $0.4 \mu \mathrm{M}$. For each interferent, Brown-Forsythe and Welch ANOVA (parametric; unmatched) statistical analysis was performed with Holm-Sidak's multiple comparison tests, where ns, $*$, $* *, * * *$ and \# correspond to $\mathrm{p}>0.05, \mathrm{p} \leq 0.05, \mathrm{p} \leq 0.01, \mathrm{p} \leq 0.001$ and and $\mathrm{p} \leq 0.0001$, respectively. 

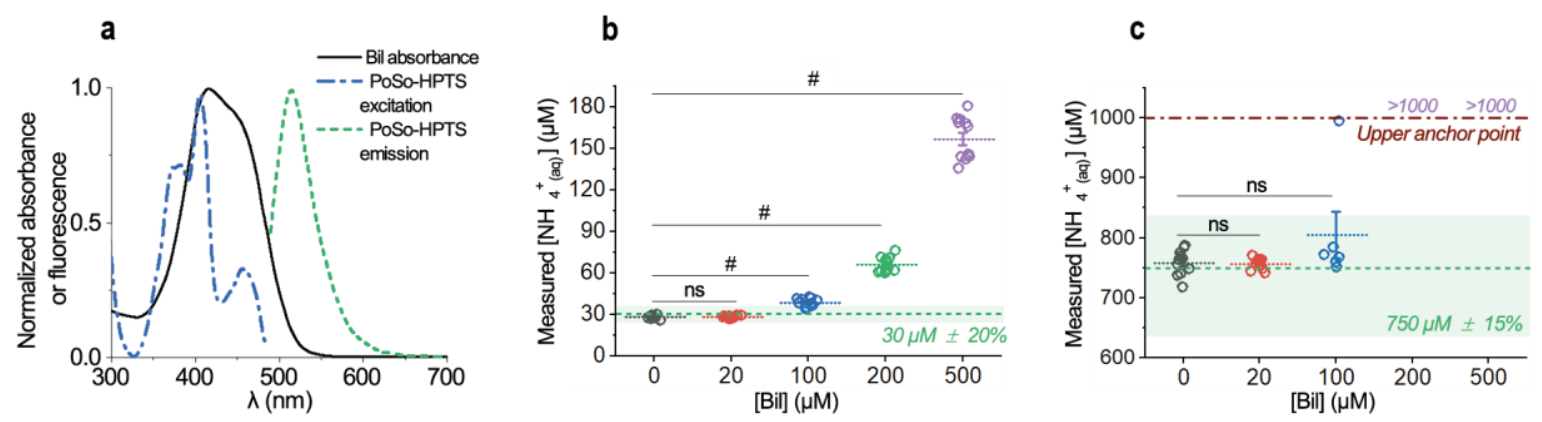

Figure 5. Reducing Bil interference in the PoSo-HPTS ammonia assay. a) Normalized spectra of Bil absorbance and PoSo-HPTS fluorescence excitation $\left(\lambda_{\mathrm{em}}=515 \mathrm{~nm}\right)$ and emission $\left(\lambda_{\text {exc }}=455 \mathrm{~nm}\right)$ spectra. $\left.\mathbf{b}-\mathbf{c}\right)$ Measured $\left[\mathrm{NH}_{4}{ }^{+}{ }_{(\mathrm{aq})}\right]$ in the absence and presence of various Bil concentrations in solutions containing $30 \mu \mathrm{M}$ (b) or $750 \mu \mathrm{M}$ (c) $\mathrm{NH}_{4}{ }^{+}$(aq) in PBS using PoSoHPTS with adjusted conditions to reduce Bil interference (i.e. $\mathrm{pH}_{\text {in }} 6.0, \mathrm{pH}_{\text {out }} 8.2, \varphi=40$ vol\%, $\left.[\text { HPTS }]_{\text {in }}=2.5 \mathrm{mM},[\text { HPTS }]_{\text {assay }}=2.5 \mu \mathrm{M}\right)$. Results are shown as exact measured values and mean \pm SD. The nominal $\left[\mathrm{NH}_{4}{ }^{+}{ }_{(a q)}\right]$ with $\pm 20 \%$ (b) or $\pm 15 \%$ (c) $\mathrm{RE}$ is depicted as green dashed line and shaded area. Assay-determined $\left[\mathrm{NH}_{4}{ }^{+}{ }_{(\mathrm{aq})}\right]$ beyond the upper anchor point are indicated as ">1000". Brown-Forsythe and Welch ANOVA (parametric; unmatched) statistical analysis was performed with Holm-Sidak's multiple comparison tests, where ns and \# correspond to $p>0.05$ and $p \leq 0.0001$, respectively. 

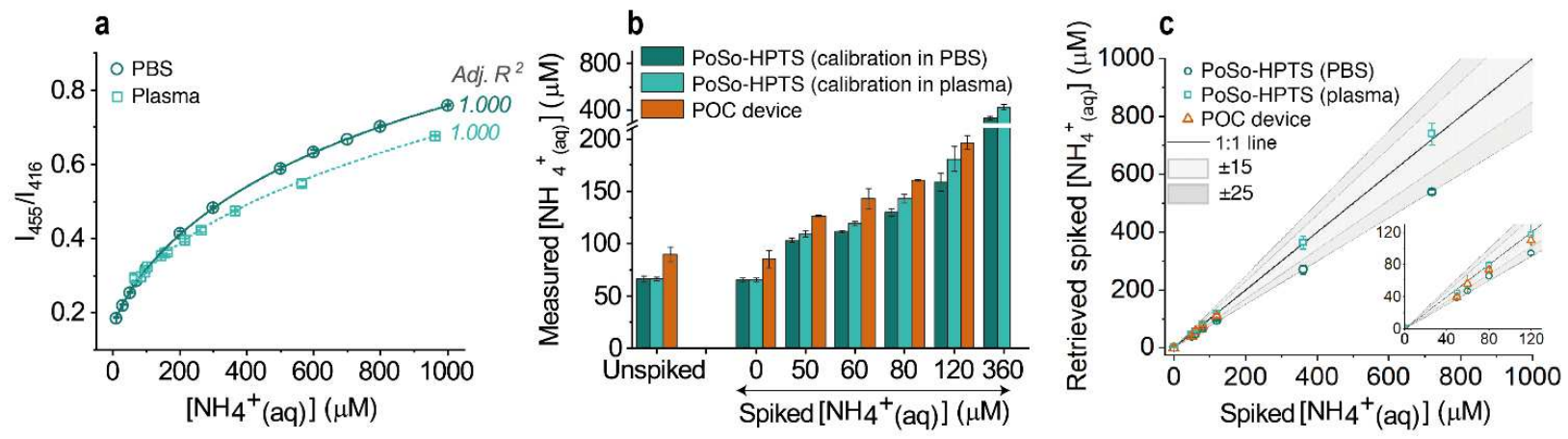

Figure 6. Ammonia measurements in plasma with PoSo-HPTS and a POC device.

a) Ammonia sensing calibration curves obtained with sigmoidal regression fit of the measured fluorescence intensity ratio $\mathrm{I}_{455} / \mathrm{I}_{416}\left(\lambda_{\text {em }}=515 \mathrm{~nm}\right)$ data plotted over $\left[\mathrm{NH}_{4}{ }_{(\mathrm{aq})}\right]$ in the calibrant solutions which were prepared either in PBS or in healthy human plasma. Results correspond to mean $\pm S D(n=3)$ of replicate wells. Conditions: $\mathrm{pH}_{\text {in }} 6.0, \mathrm{pH}_{\text {out }} 8.2, \varphi=40$ vol\%, $[\text { HPTS }]_{\text {in }}=2.5 \mathrm{mM},[\text { HPTS }]_{\text {assay }}=2.5 \mu \mathrm{M}$. b) $\left[\mathrm{NH}_{4}{ }^{+}{ }_{(\mathrm{aq})}\right]$ in unspiked and ammonia-spiked healthy human plasma samples as measured by the PoSo-HPTS assay using the calibration curves from (a) and by the POC device. Results correspond to mean $\pm S D(n=4$ independent replicate solutions (PoSo-HPTS); $n=2$ independent replicate solutions (POC device)). c) Retrieved spiked $\left[\mathrm{NH}_{4}{ }_{(}{ }_{(a q)}\right]$ from (b) as a function of the nominal spiked $\left[\mathrm{NH}_{4}{ }^{+}{ }_{(\mathrm{aq})}\right]$. The " $1: 1$ " black line corresponds to the ideal case where the retrieved spiked $\left[\mathrm{NH}_{4}{ }^{+}\right.$(aq) $]$equals the nominal one and grey areas indicate the corresponding $\pm 15 \%$ and $\pm 25 \%$ RE. Inset shows the same data but only up to $120 \mu \mathrm{M} \mathrm{NH}_{4}{ }^{+}{ }_{(\mathrm{aq})}$. Mean $\pm \mathrm{SD}(\mathrm{n}=4$ (PoSo-hCy); $\mathrm{n}=2$ (POC)). 

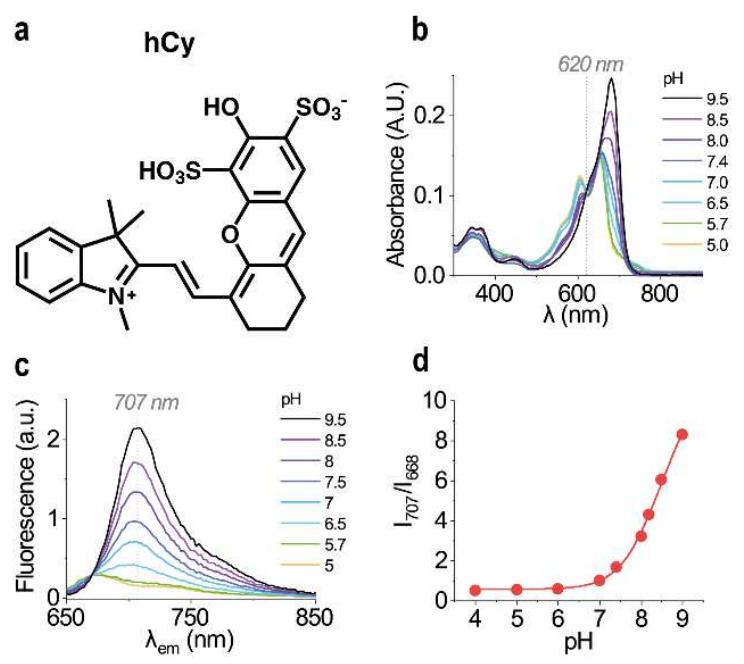

Figure 7. Alternative fluorescent dye to overcome bilirubin interference. a) hCy structure; the product consists of a mixture of disulfonation isomers. $\mathbf{b}, \mathbf{c}$ ) Absorbance (b) and fluorescence emission (c) spectra of free hCy in aqueous solutions of various $\mathrm{pH}$ $([\mathrm{hCy}]=10 \mu \mathrm{M})$. d) Fluorescence intensity ratio $\mathrm{I}_{707} / \mathrm{I}_{668}\left(\lambda_{\mathrm{exc}}=630 \mathrm{~nm}\right)$ as a function of $\mathrm{pH}$ for free hCy. 
a

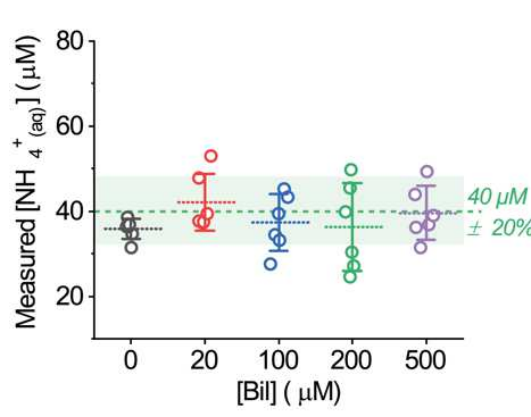

b

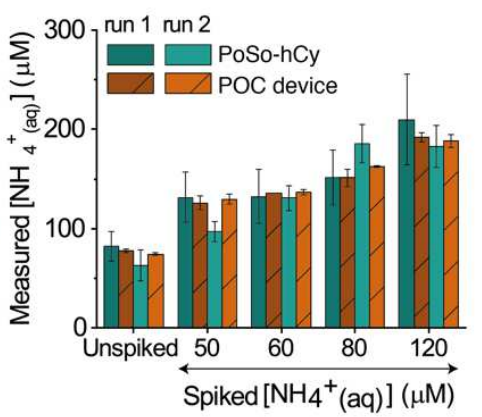

C

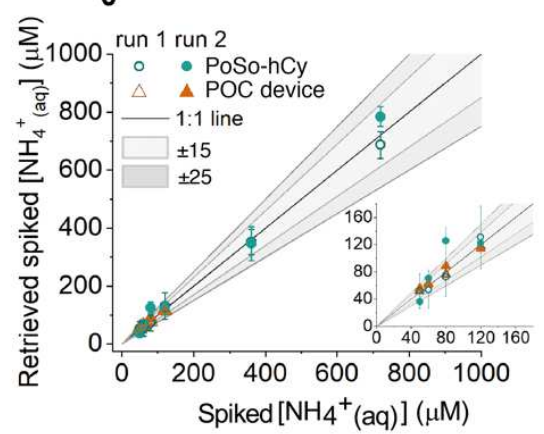

Figure 8. Alleviation of bilirubin interference and ammonia measurements in plasma with PoSo-hCy and a POC device. a) $\left[\mathrm{NH}_{4}{ }^{+}{ }_{(\mathrm{aq})}\right]$ measured using PoSo-hCy in solutions containing $40 \mu \mathrm{M} \mathrm{NH}_{4}{ }^{+}{ }_{\text {(aq) }}$ and various concentrations of Bil in PBS. Calibration curve from Supplementary Figure S11 was used. Results are shown as exact measured values and mean $\pm S D(n=6)$ of independent replicate solutions. The nominal $\left[\mathrm{NH}_{4}{ }^{+}{ }_{(\mathrm{aq})}\right]$ with $\pm 20 \% \mathrm{RE}$ is depicted as green dashed line and shaded area. Brown-Forsythe and Welch ANOVA (parametric; unmatched) statistical analysis was performed with Holm-Sidak's multiple comparison tests, indicating non-significant differences compared to the control $(p>0.05)$ for all [Bil]. b) $\left[\mathrm{NH}_{4}{ }^{+}\right.$(aq) $]$in unspiked and ammonia-spiked healthy human plasma samples as measured by the PoSo-hCy assay and the PocketChem device in two independent experiments (runs 1 and 2). For each run, data are presented as mean \pm SD ( $n=4$ independent replicate solutions (PoSo-hCy); $n=2$ independent replicate solutions (POC device)). c) Retrieved spiked $\left[\mathrm{NH}_{4}{ }^{+}{ }_{(\mathrm{aq})}\right]$ from (b) as a function of the nominal spiked $\left[\mathrm{NH}_{4}{ }^{+}{ }_{(\mathrm{aq})}\right]$. The " $1: 1^{\text {" black line }}$ corresponds to the ideal case where the retrieved spiked $\left[\mathrm{NH}_{4}{ }^{+}\right.$(aq) $]$equals the nominal one and grey areas indicate the corresponding $\pm 15 \%$ and $\pm 25 \%$ RE. Inset shows the same data but only up to $160 \mu \mathrm{M} \mathrm{NH}_{4}{ }^{+}{ }_{\text {(aq) }}$. Mean $\pm \mathrm{SD}$ ( $\mathrm{n}=4$ (PoSo-hCy); $\mathrm{n}=2$ (POC)). Conditions: $\mathrm{pH}_{\text {in }}$ 6.5, $\mathrm{pH}_{\text {out }} 9.5, \varphi=40 \mathrm{vol} \%,[\mathrm{hCy}]_{\text {in }}=250 \mu \mathrm{M},[\text { Polymer }]_{\text {assay }}=1.3 \mathrm{mg} / \mathrm{mL}, 200 \mu \mathrm{L} /$ well. 

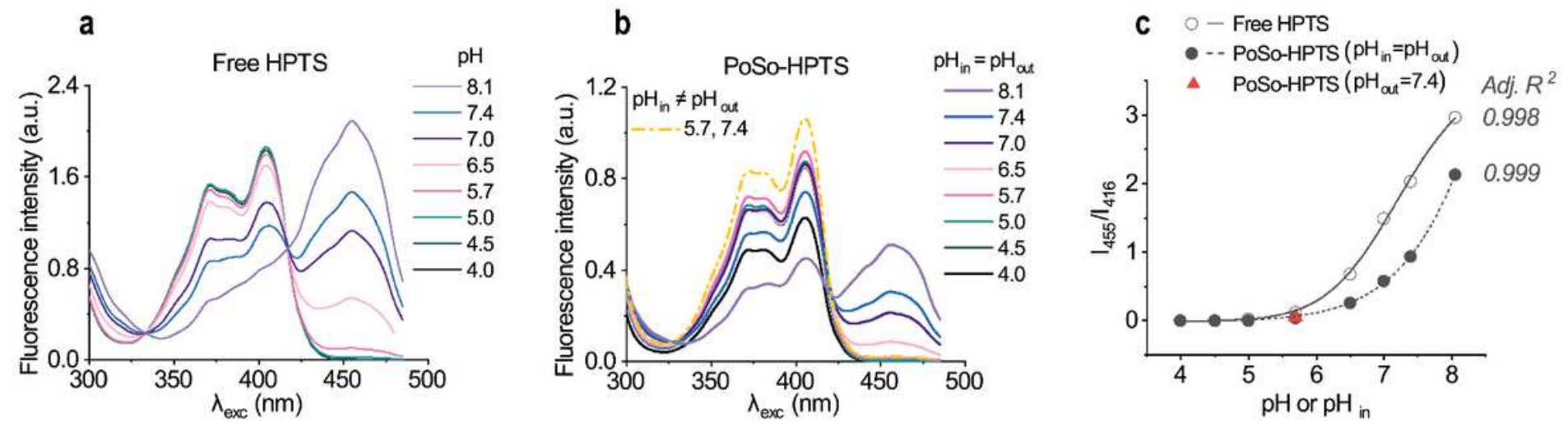

Figure 1

Please see the Manuscript PDF file for the complete figure caption

a

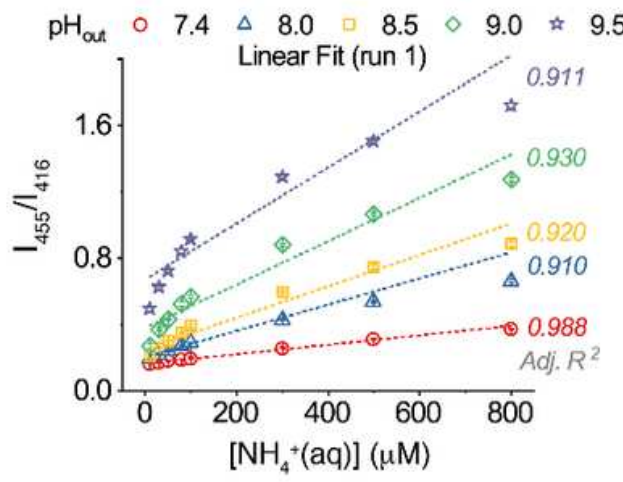

C
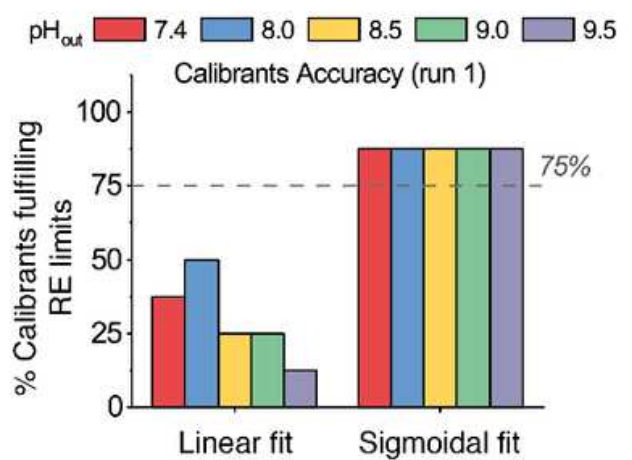

Figure 2

Please see the Manuscript PDF file for the complete figure caption
Sigmoidal Fit (run 1)

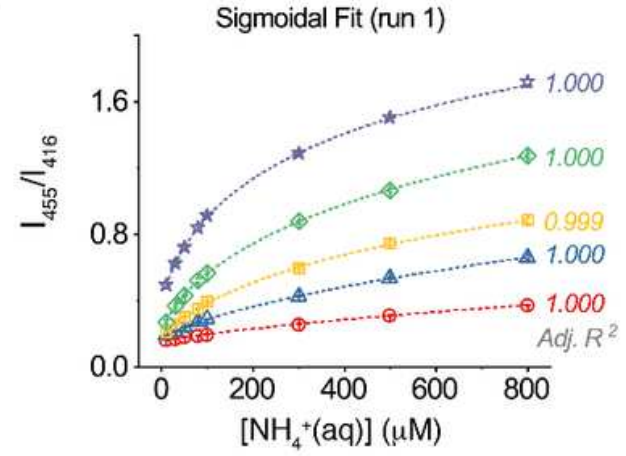

d
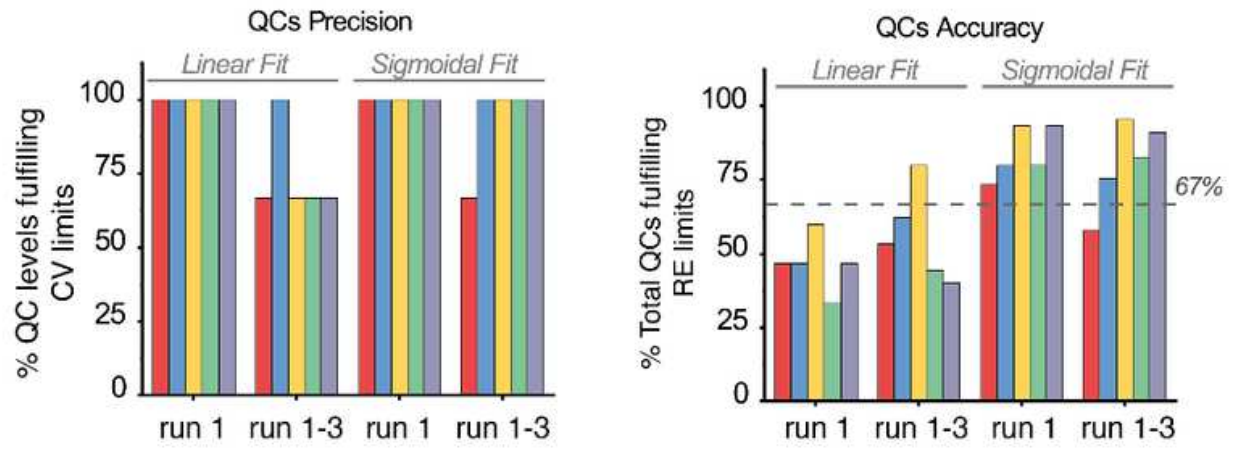
a $\varphi($ vol\% $\quad=10 \Delta 25 \star 40$ b $\mathrm{pH}_{\text {out }} 8.0 ; 8.2 ; 8.5$
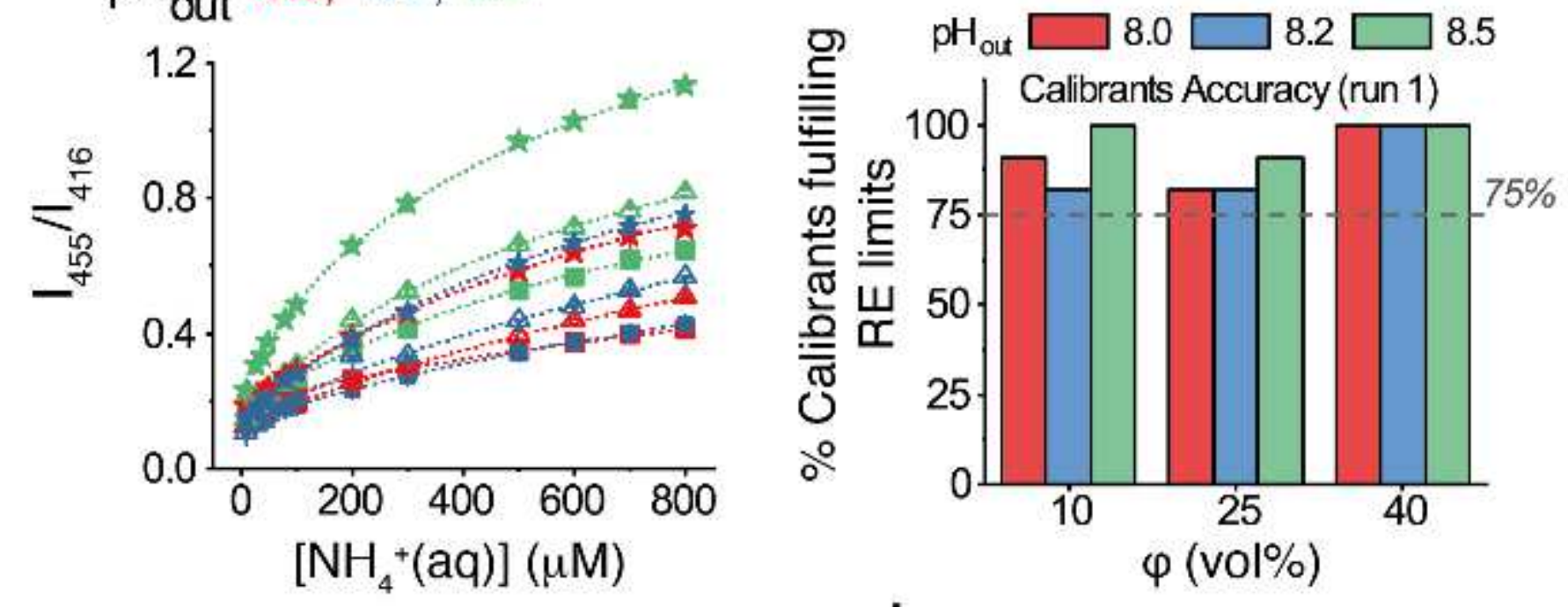

C
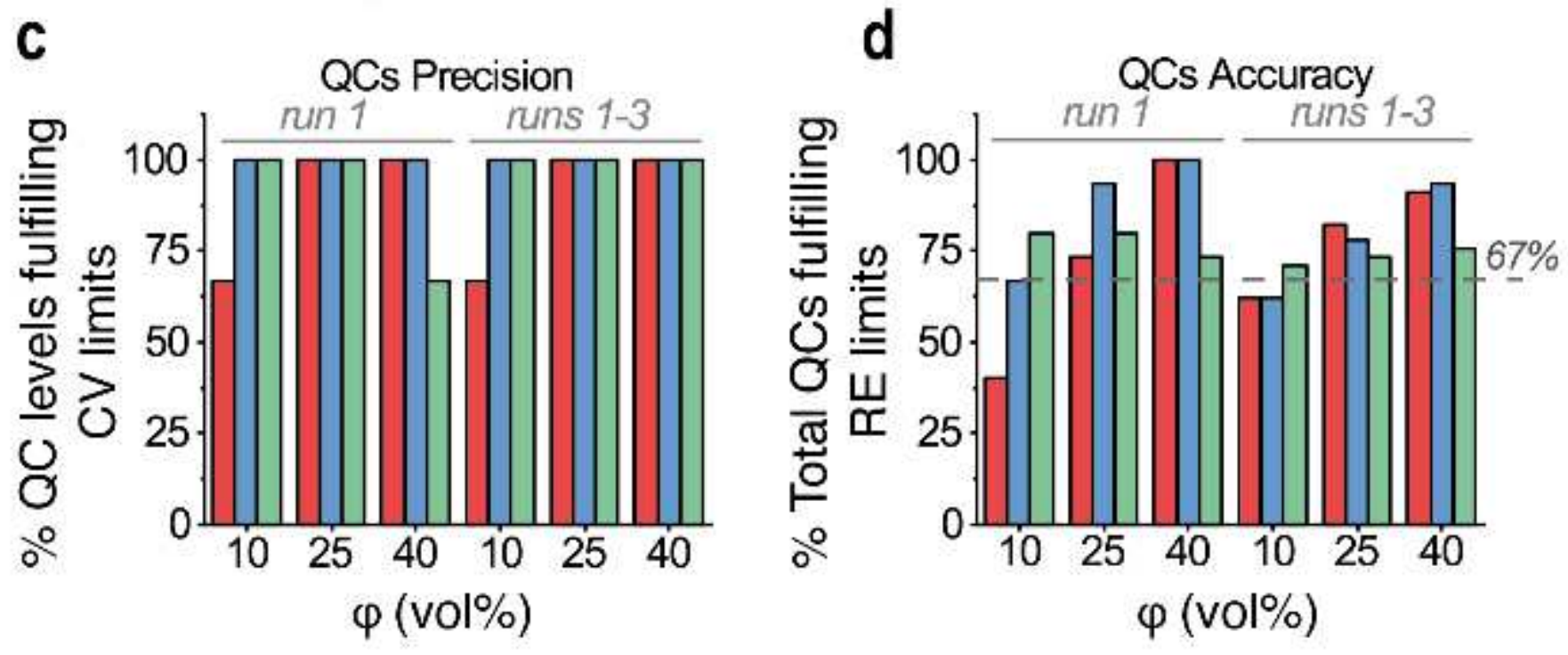

Figure 3

Please see the Manuscript PDF file for the complete figure caption 
a

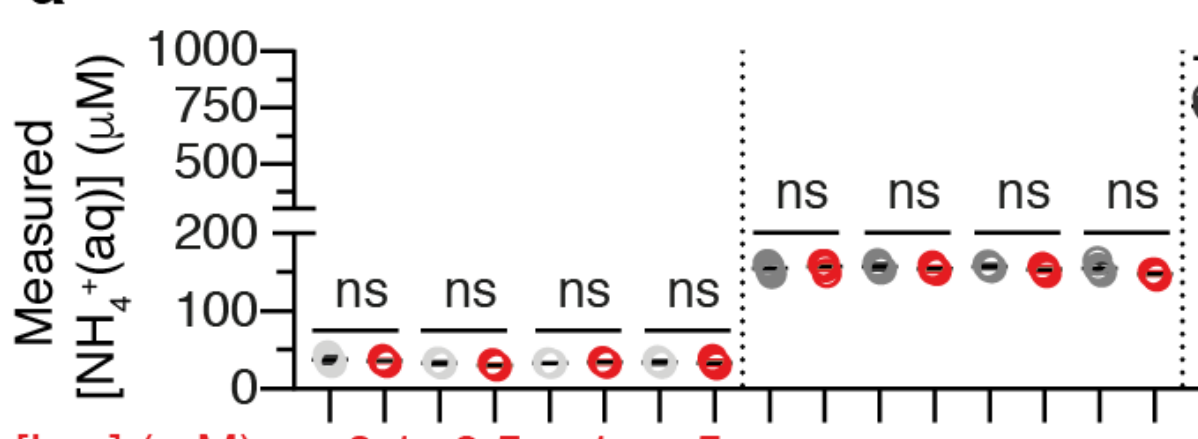

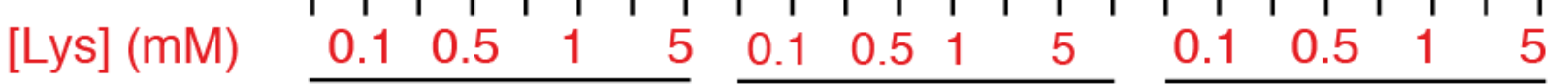

$\left[\mathrm{NH}_{4}{ }^{+}(\mathrm{aq})\right](\mu \mathrm{M}) \quad 30 \quad \frac{0.1}{150} \quad \frac{0.1}{750}$
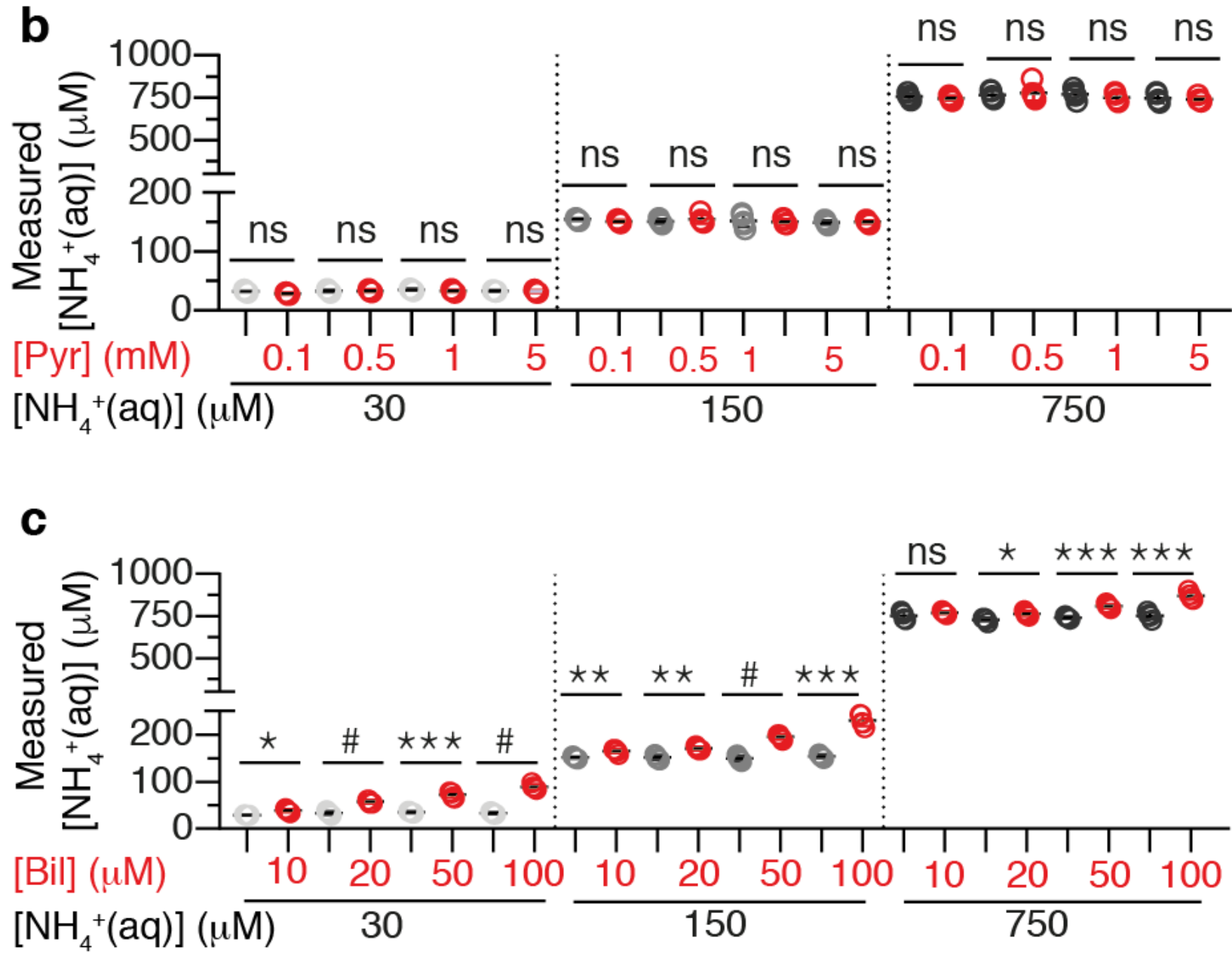

Figure 4

Please see the Manuscript PDF file for the complete figure caption 
a

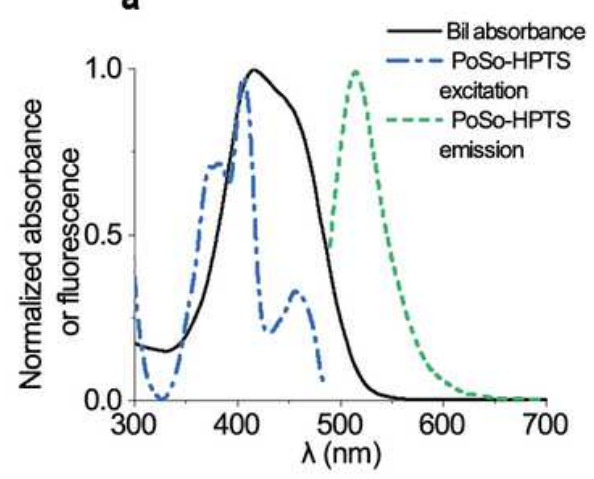

b

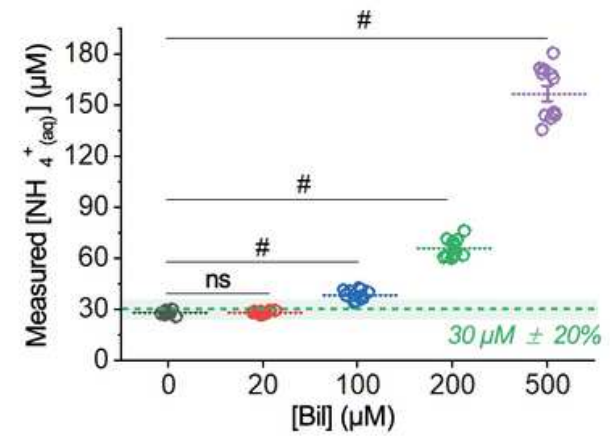

C

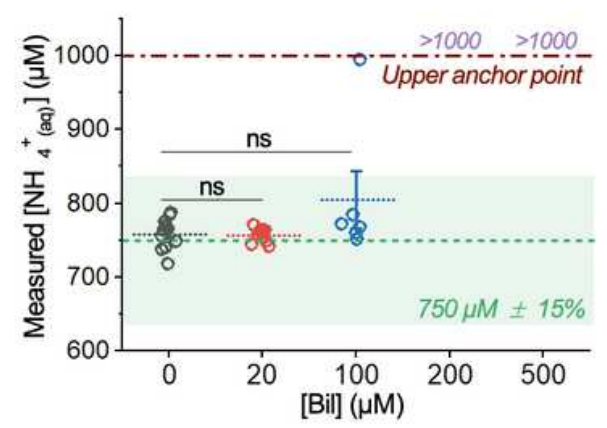

Figure 5

Please see the Manuscript PDF file for the complete figure caption
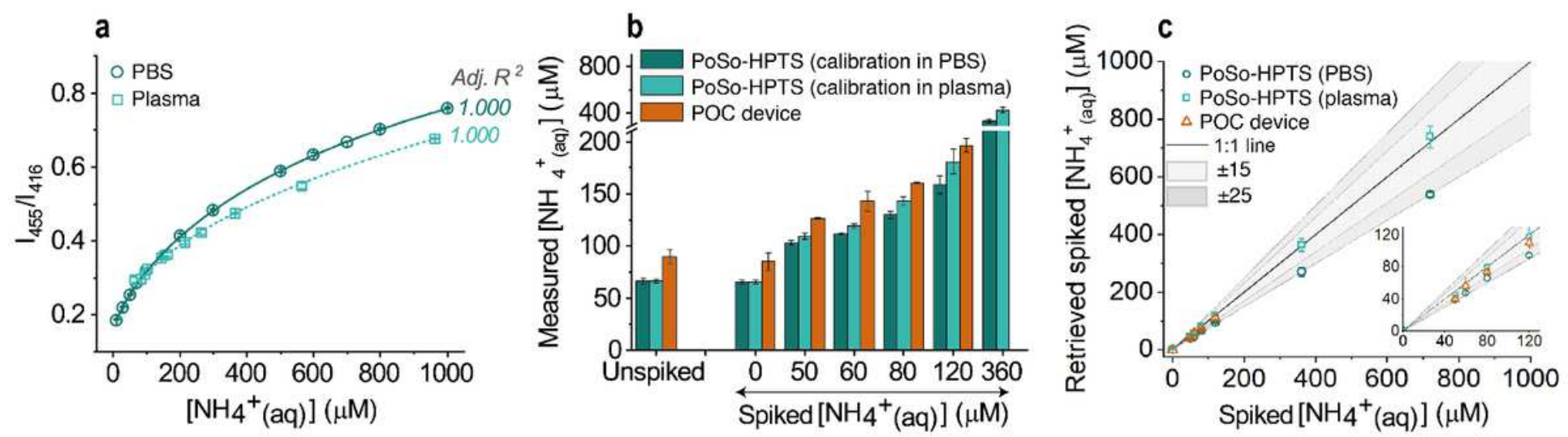

Figure 6

Please see the Manuscript PDF file for the complete figure caption 

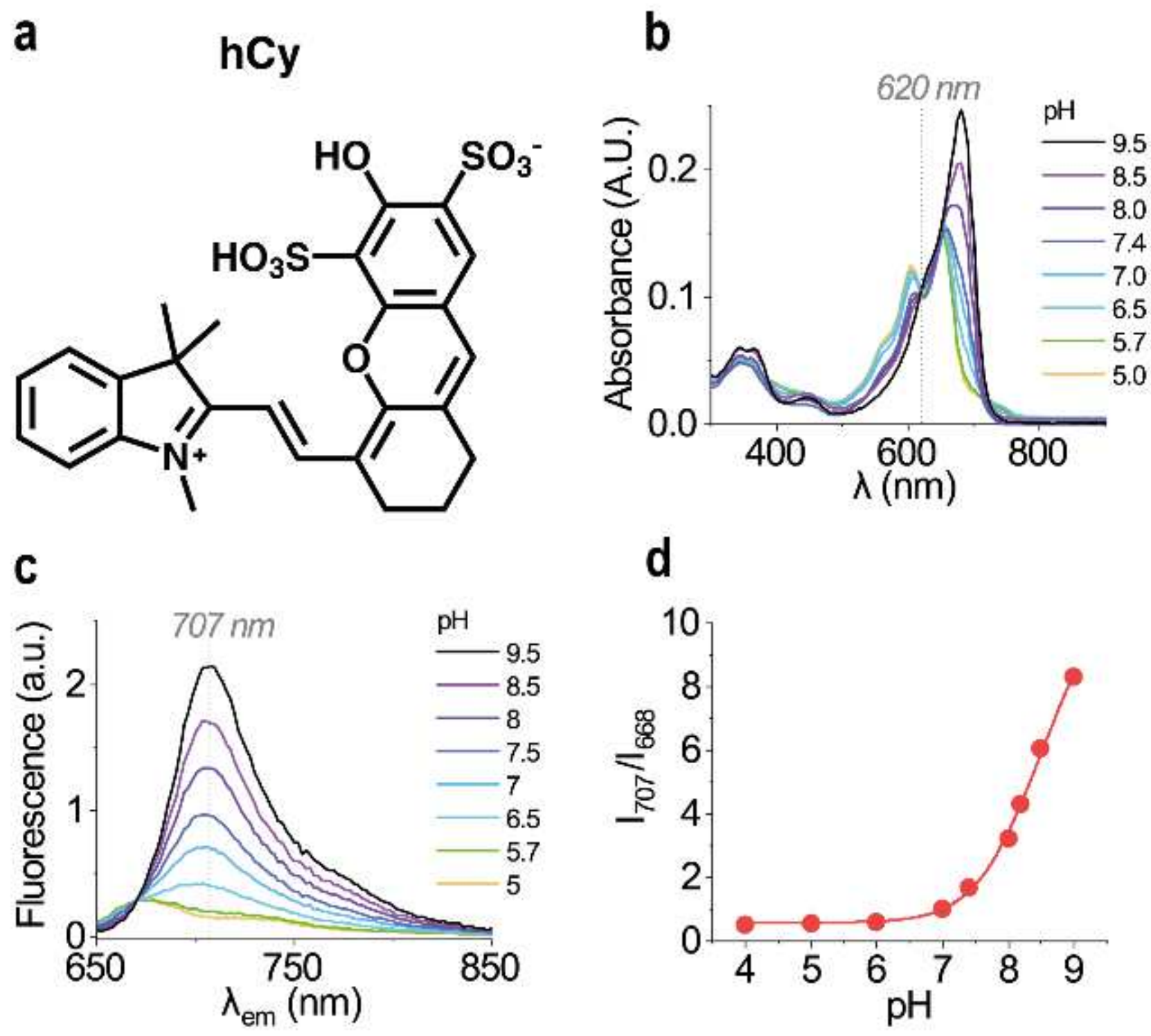

Figure 7

Please see the Manuscript PDF file for the complete figure caption
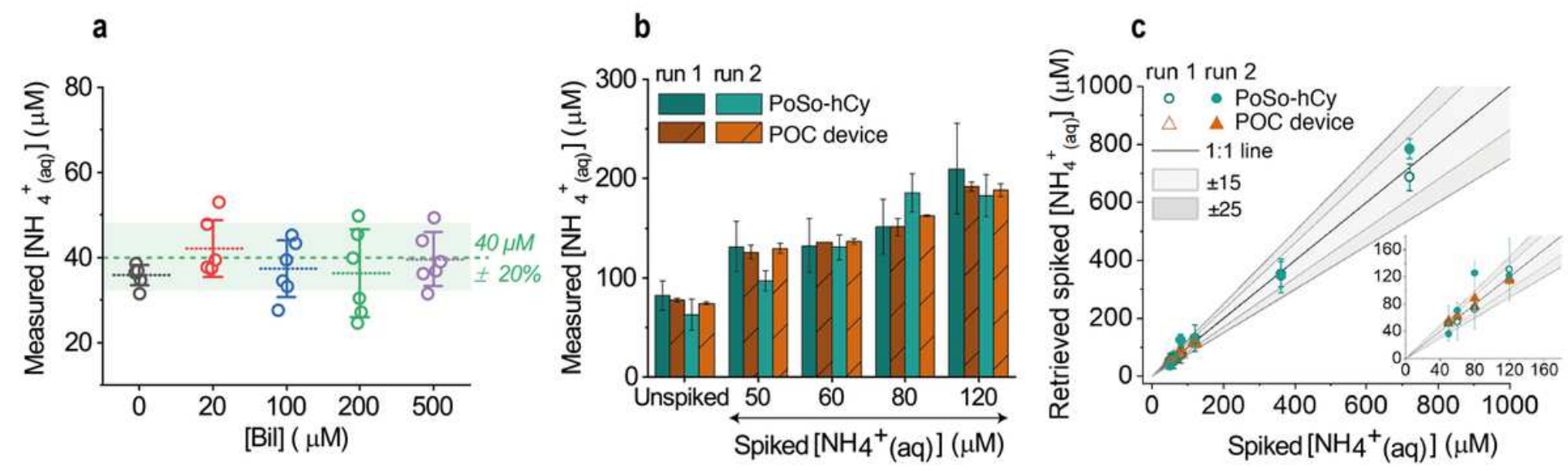
Figure 8

Please see the Manuscript PDF file for the complete figure caption

\section{Supplementary Files}

This is a list of supplementary files associated with this preprint. Click to download.

- SpyrogianniGourmeletalSupplementaryInformation.docx 